\title{
A review of theoretical salt weathering studies for stone heritage
}

\author{
Chiaki T. Oguchi ${ }^{*^{*}}$ (D) and Swe Yu
}

\begin{abstract}
Salt weathering can cause substantial deterioration of natural rocks, building stones, masonry materials, monuments, and engineering structures. Nearly two centuries of salt weathering studies, both theoretically and empirically, have manifested its power as well as its complexity. This paper attempts to unite the kinds of literature assess the various theories in the light of the combined information. The theoretical approaches concerning the most cited mechanisms of salt weathering such as crystallization, hydration and thermal expansion of crystalline salts are thoroughly reviewed. It is understood that there is no universally acceptable hard and sound theoretical information on this topic yet. More precise theories should be developed to elucidate the complications of the mechanisms of salt weathering as well as to interpret the results of empirical studies.
\end{abstract}

Keywords: Salt weathering theories, Crystal growth pressure, Hydration, Thermal expansion of salt

\section{Introduction}

Salt weathering has been implicated as a cause of rock disintegration since the time of Herodotus, and systematic investigations of salt weathering have been performed over at least 200 years (e.g., Thury 1828; Miller 1841; Luquer 1895; Cooke 1979; Goudie and Viles 1997; Williams and Robinson 2001; Doehne 2002; Tsui et al. 2003; Van Grieken 2003; Coussy 2006; Espinosa-Marzal and Scherer 2010; Shahidzadeh-Bonn et al. 2010; Flatt et al. 2017). In the nineteenth and twentieth centuries, the great German desert geomorphologists (e.g., Penck 1891; Passarge 1904; Mortensen 1933) and various French geomorphologists (e.g., Birot 1954; Pedro 1957a, 1957b; Tricart 1960) greatly extended our knowledge of salt weathering. Since the middle of the twentieth century, the majority of research work has been done in Europe (e.g., Goudie et al. 1970; Kwaad 1970; Theoulakis \& Moropoulou 1997; Williams and Robinson 1981; Coussy 2006; Espinosa-Marzal and Scherer 2010; Flatt et al. 2017). Further interest in the field was sparked by

\footnotetext{
* Correspondence: ogchiaki@mail.saitama-u.ac.jp

${ }^{1}$ Graduate School of Science and Engineering, Saitama University,

Shimo-Okubo 255, Sakura-ku, Saitama 338-8570, Japan

Full list of author information is available at the end of the article
}

the exploration of theories behind salt weathering (Correns 1949; Weyl 1959; Wellman and Wilson 1965).

Many field and laboratory studies over the last few decades have also shown weathering of salt, regardless of the mechanisms involved (Evans 1970; Mustoe 1982, 1983; Pye and Sperling 1983; Goudie 1985; Rögner 1986; Trenhaile 1987; Yatsu 1988; Matsukura and Kanai 1988; Cooke et al. 1993; Thaulow \& Sahu 2004; McGreevy 1996; McGreevy \& Smith 1982; Goudie 1986, 1993, 1999; Goudie and Viles 1997; Robinson \& Williams 1996, 1982, 2000; Williams \& Robinson 1998). It is a highly destructive process that is particularly important in rock decay in a wide range of environments including Mars (Malin 1974). Types of decay due to salt weathering are shown as Fig. 1. These are supposed to be reflected by salt weathering processes. Furthermore, salt weathering plays a role in the development of many geomorphologic features, such as alveoles and honeycombs (Mustoe 1982), tafoni and cavernous weathering (Bradly et al. 1978), and pedestal rocks (Chapman 1980) (Fig. 2). This type of weathering is also an important contributor to the production of rock meals and debris, especially in arid regions (Beaumont 1968; Goudie 1977, 1983; Goudie et al. 1979, 1984, 1997; Goudie and Day 1980; Goudie \& Cooke 1984; Goudie \& Watson 1984; Punuru 

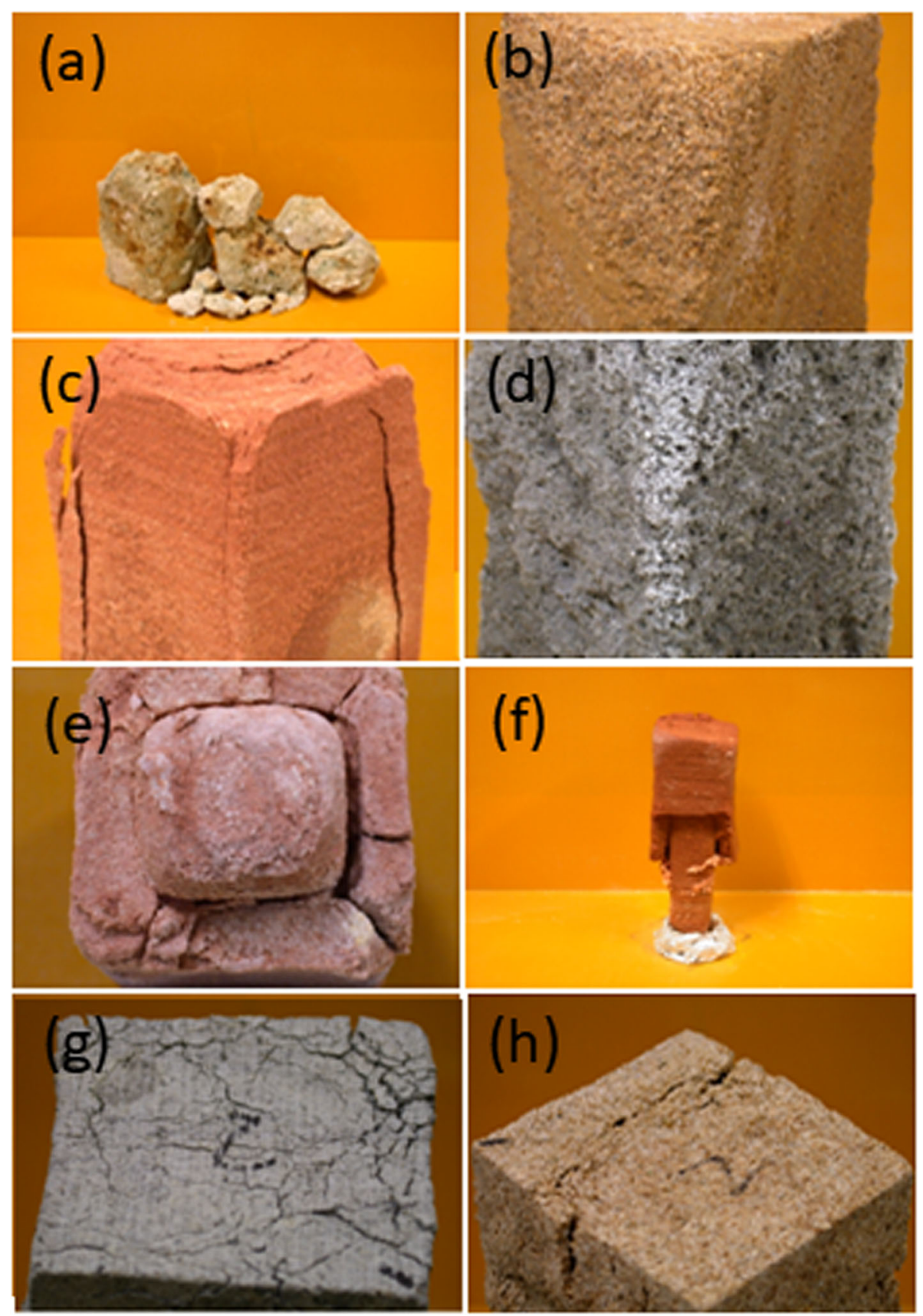

Fig. 1 Patterns of disintegration due to weathering. a Cracking and disintegration, b crumbling, c scaling, $\mathbf{d}$ surface pitting, e thick scaling, $\mathbf{f}$ delamination, $\mathbf{g}$ cracking, and $\mathbf{h}$ expansive dilatation patterns. Scale bar shows $10 \mathrm{~mm}$

et al. 1990; Goudie \& Viles 1995), coastal areas (Mottershead 1989; Cardelle et al. 2003), and Antarctica (Prebble 1967). Salt weathering may be a common planetary phenomenon and could be responsible for some aspects of the Martian landscape (Malin 1974; Clark and Van Hart 1981; Clark 1998).

Salt weathering of building stones is a primary cause of the loss of historic architecture (Evans 1970; Winkler 1973; Amoroso and Fassina 1984; Smith and
McGreevy 1988; Winkler 1994; Cooke 1994; Price 1996; Cooke and Gibbs 1993; Gomez-Heras \& Fort 2007) and many structures in archeological sites have been damaged by this process (Lucas 1925; Winkler 1975; Goudie 1977). Salt also has a major impact on civil engineering because it damages roads, highways, runways, dams, and building foundations (Netterberg and Loudon 1980; Sayward 1984; Obika et al. 1989; Doornkamp and Ibrahim 1990; Goudie and Viles 1997). In hot, 


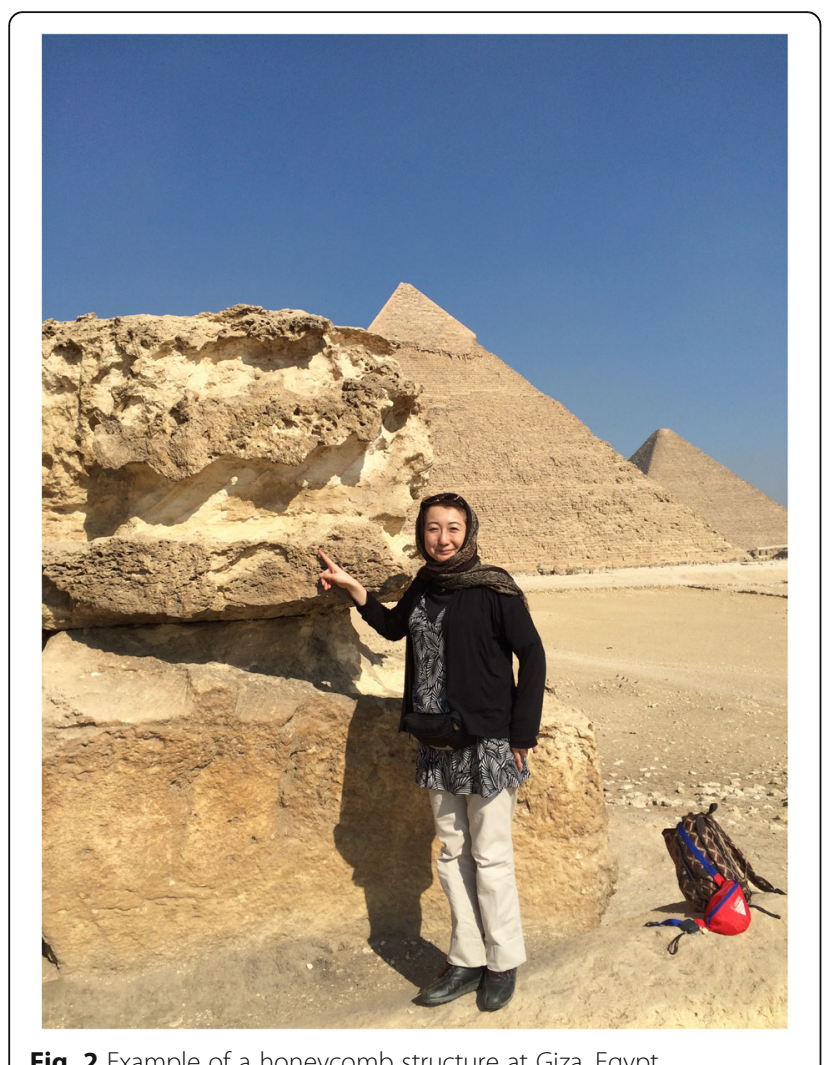

Fig. 2 Example of a honeycomb structure at Giza, Egypt

arid areas, such as the Middle East, the full significance of salt weathering as an engineering hazard became evident after the construction boom of the 1970s and 1980s (Doornkamp and Ibrahim 1990).

Despite nearly two centuries of research and observation, there is still no definitive way to overcome salt weathering. As a result of intensive reviews and textbooks around every decades such by Evans (1970), Winkler (1994), Goudie and Viles (1997), Doehne and Price (2010), and Siegesmund and Snethlage (2014), these studies have been able to be introduced, categorized or organized as focusing to theory, mechanisms, experimental methods, research tools, and so on. The present paper also reviews many studies even though not enough, to summarize the research history of salt weathering, including the subsequent research results. In orderthe construction boom of the 1970s to find a breakthrough to conquer the deterioration of stone and related materials for future issues, this review is expected to help a little in solving future problems.

\section{Substances involved in salt weathering}

\subsection{Moisture}

A crucial factor affecting the effectiveness of salt weathering is the presence of moisture and its movement. Moisture can either provide a source of salt or mobilize and deposit salt in pores and cracks because only salts dissolved in water can enter and move through porous bodies. Although moisture itself may also substantially diminish the mechanical resistance of some rocks and stones, its distribution in the porous material determines the area where deterioration occurs. This area corresponds to the zone of maximum moisture content (Snethlage and Wendler 1997) and refers not only to the damage at the base of a wall with rising damp, as described by Arnold (1982), but also to the formation of gypsum veils at the top of the rising damp area, as discussed by Zehnder $(1993,1996)$.

The main moisture sources that merit consideration are dew, fog, rain, and groundwater. In some desert areas, dewfall enhances the salt weathering processes and fog water is of special importance in coastal deserts. Of all these sources, groundwater may be the most important. Ground moisture comes from rain splashing against the base of a building and from groundwater rising by capillary suction. Both types of moisture may contain more ions than (Meredith \& Donald 1995) surface water because they can contain salts from streets and sidewalks or from the slow circulation of undersaturated groundwater between the mineral particles of soils. As the groundwater moves through the stone, the salts may crystallize and effloresce near or on the stone surface. If those salts are soluble, they are dissolved again and infiltrate the ground. Therefore, groundwater is also a major source of salts in suitable topographic situations (e.g., sabkhas zones of the Middle East), and the presence of high groundwater levels is a prime determinant of the efficacy of salt weathering of engineering structures. Cooke et al. (1982) reported that aggressive soil conditions constituting an engineering hazard were produced when saline groundwater was drawn upward through the soil to produce a capillary fringe that either reached the ground surface or was sufficiently close to it to affect foundations.

Water can enter a porous material either as a vapor or liquid. In the vapor state, the main mechanisms by which water can penetrate a porous material are condensation and hygroscopicity. Condensation is categorized as surface condensation and capillary condensation (microcondensation) in pores, which are well-understood, distinct processes (Cammuffo 1988). Adsorption of moisture or surface condensation occurs in warm humid air when moisture meets a cooler surface or by cooling of the air. Moisture also adsorbs readily to capillary walls in an oriented manner owing to the electrostatic attraction in capillaries $0.1 \mu \mathrm{m}$ or smaller, which can cause stone decay by moisture expansion.

Salts can also absorb moisture, especially when the ambient relative humidity becomes higher than their equilibrium relative humidity (ERH). Under highhumidity conditions, salts may be hygroscopic or 
deliquescent. Hygroscopic salts absorb moisture from the air, but not enough to form a solution, whereas deliquescent salts absorb sufficient moisture to form a solution.

Because concentrated salt solutions have a lower vapor pressure than does pure water, they have a higher tendency to condense water vapor from the environment to equalize the activity of water in the solution with that in the vapor phase to reach equilibrium. This process has also been called classical osmosis, particularly in German texts (Weber 1984).

In the liquid state, water movement can occur via capillarity and infiltration mechanisms. The capillarity mechanism arises from the attraction of the water and the capillary material, as well as the surface tension of the liquid, whereas the infiltration mechanism requires hydrostatic pressure and depends on the permeability of the material (Vos 1976; Amoroso and Fassina 1984; Weber 1984; Massari and Massari 1993). The rise of ground moisture by the capillarity mechanism can lead to slow, progressive salt impregnation (Fig. 3). This upward movement of capillary water through surface and near-surface materials is sometimes called evaporative pumping and is the product of high surface temperatures.

The height of the capillary rise, that is, the thickness of the capillary fringe, depends on the soil temperature gradient and the nature of the soil, and it is normally less than a meter in clean gravel, although it is up to $10 \mathrm{~m}$ in clay. Cooke et al. (1982) suggested that the capillary rise under desert conditions is normally no more than 2$3 \mathrm{~m}$, and rarely, if ever, exceeds $4 \mathrm{~m}$. In some buildings, the thickness of the capillary zone may be exceptionally and unexpectedly high, sometimes exceeding $6 \mathrm{~m}$ (Cooke 1994). The maximum height of the capillary rise is often marked by a white rim of efflorescence with a dark wet outer rim that remains wet owing to the effect of hygroscopic salts. The moisture can be retained, especially in fine-grained masonry, stone, concrete, and mortar. Other complications may arise, with the surface concealment of capillaries by lichens and mosses, which retain moisture and do not permit evaporation from the open ends of the channels, keeping the wall wet.

Alves et al. $(2011,2013)$ investigated the pore network of several types of stone in laboratory experiments and found that durability is controlled by porosity. The order of porosity values from high to low, of limestones, marbles, and granites matched that of durability. These experiments also showed that in addition to porosity, further analysis of pore size distribution and specific surface area is important for understanding the pore network of building stones. Benavente (2011) summarizes the importance of measuring the pore size distribution in building stone deterioration. The main processes are categorized in the order of pore size (Fig. 3). De Kock et al. (2017) investigated sandstone in Belgian heritage and highlighted the importance of pore size based on their measurement of rock properties. Capillary pores adsorb and desorb water according to the relative humidity (RH). This water adsorption interferes with water vapor diffusion and affects critical water content. Stones with a high number of capillary pores are more prone to adsorbing moisture and are difficult to dry out completely. Finally, the connectivity between all the different pores and pore sizes defines the overall effect of water.

These studies demonstrate that it is important to understand how water moves inside a porous material. If it moves as a liquid, it can transport salts, whereas if it moves as a vapor, it may be retained through hygroscopicity. Liquid water is governed by a capillarity mechanism and water vapor is governed by a diffusion mechanism. The transition point between these two mechanisms defines the critical moisture content, $\Psi_{\mathrm{c}}$, of a porous material. This parameter is constant for each material and depends mainly on porosity and pore size distribution (Snethlage and Wendler 1997). The actual distribution of moisture in stone depends on porosity, pore size distribution, and environmental conditions. As Snethlage and Wendler (1997) discuss, the maximum of moisture content resulting from wet-dry cycling is closer to the surface in denser stones, and deeper and broader in coarse, porous materials.

\subsection{Sources of salts}

Salts can originate from various sources (Price 1996). Solutions of ions, from which two or more destructive salts may crystallize on or in rock surfaces, may originate from the following sources: from the rock and be drawn to the surface by evaporation, from overlying beds and run down the face of the rock, and from the atmosphere as airborne materials, such as sea spray, sea splash, aerosol, or the reworking of other deposits, and be deposited directly on the rock surface. Several salts may crystallize depending on the composition of the solution and on the environmental conditions.

Important sources of salts include atmospheric pollution, groundwater, seawater, rainwater, rock salts and deicing salts, building materials, organic/biological metabolism, and inappropriate treatments with incompatible conservation products. The salts that form depend on the ions present, their relative abundance, and environmental conditions that favor evapotranspiration, such as temperature and $\mathrm{RH}$.

Gaseous pollutants, such as sulfur dioxide and nitrogen oxides, and acids, such as sulfuric, nitric, and hydrochloric acid, all contribute to salt weathering. Particulates or aerosols, such as carbonaceous spheres, and oxidants, such as ozone produced by photochemical reactions, may act as important catalysts. For example, sulfur dioxide reacts with dust and other particles and with reactive materials, 

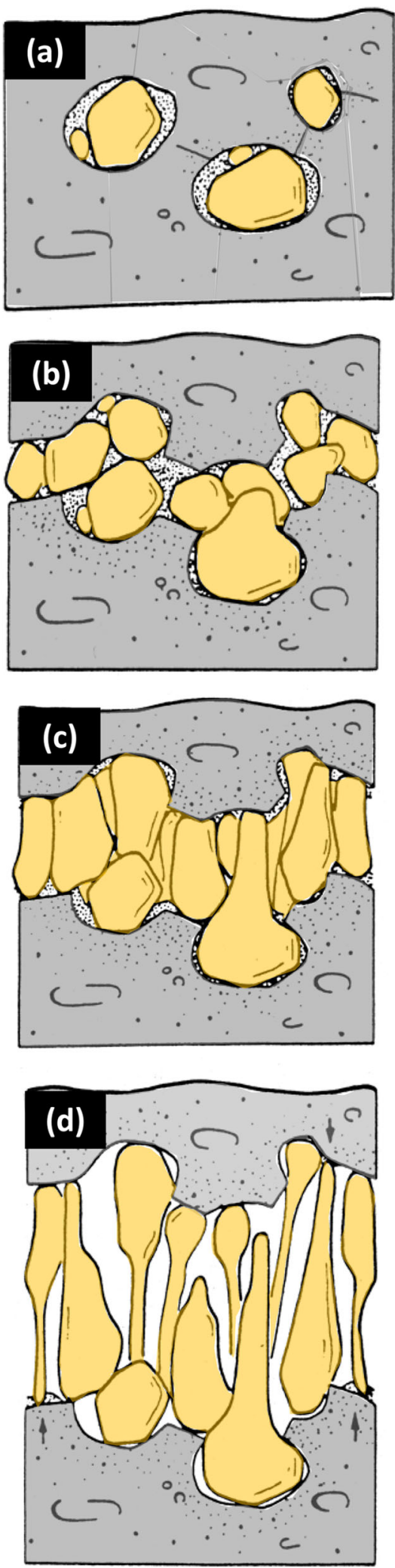

Fig. 3 Model of the disruption process by crystallizing salts (modified after Zehnder and Arnold 1989). a Saline solution evaporates first from large pores, and then smaller pores, which makes salts growing in large pores form aggregates or granular crusts. $\mathbf{b}$ Cohesion or strength of the host material is reduced by disruption along cracks caused by the crystallization pressure of clustered aggregates growing on pore walls. c Crystallization concentrated in cracks continues isometrically when the crystals are covered by solution film, which produces columnar crystals when evaporation dominates. d Columnar crystal growth thins out as the cracks open, forming whisker-like crystals when their growing tips are in contact with solution, and the crystal lift debris or fragments produced by disruption of the host material

including many building stones, to form gypsum (Cammuffo et al. 1983). An important part of this process is the oxidation of sulfur dioxide, either in the gas phase or in moisture films on building stones. This oxidation is assisted by atmospheric oxidants, such as ozone and hydrogen peroxide, as well as by catalysts, such as soot or black carbon and smoke. Sulfates can attack carbonate rocks through dissolution by sulfuric or sulfurous acid and by converting calcium and magnesium carbonates to more soluble sulfates or sulfites. The sulfate attack on silicate rocks, in contrast, is not easily measured. Leaching of alkali metals and iron may occur, which often forms black crusts on the stone surface, causing discoloration. Török et al. (2011) investigated the effect of the environment on the formation of these crusts in urban and rural areas and Farkas et al. (2018) studied the crusts in different countries. Gibeaux et al. (2018) determined the pollution rates from the speed of color change measured by fixed-point observations.

Efficient automotive combustion is an important contributor of nitrogen oxides, which are readily converted to corrosive nitric acid in the presence of oxidants. Although it is also a strong acid, nitric acid is less damaging to carbonate rock than sulfuric acid and sulfates due to the greater reactivity of sulfates with stone. Hydrochloric acid, which readily dissolves carbonate rock, is an important pollutant source of chloride ions, in addition to sea spray and desert dust in many areas. Coal combustion is the major non-natural source of hydrochloric acid. All these atmospheric pollutants, after undergoing emission (from natural and anthropogenic sources), transmission (over short or long distances), immission (reaching certain local environments), and deposition (on dry and wet surfaces with variable reactivities), can cause devastating salt weathering hazards.

Groundwater is an ample source of salts because the waters in soil are dilute salt solutions. The solutions contain chloride, sulfate, nitrate, carbonate, magnesium, calcium, sodium, potassium, ammonium, and occasionally rare earth elements. Organic pollutants can produce phosphates and nitrates. Compared with normal soil solutions, those near housing and other sites used by humans are enriched in nitrate and chloride. Nitrate is 
produced by microorganisms from organic waste and chlorides come from the use of deicing salts $\left(\mathrm{NaCl}\right.$ and $\left.\mathrm{CaCl}_{2}\right)$ (Gomez-Heras et al. 2004). The salts rising from the groundwater readily join salts leached from lime mortar, cement, concrete, plaster, and deicing salts from the streets.

Sea salt in the atmosphere is the greatest contributor of salts. Sea spray from ocean waves is a salt spray that contains a high concentration of mineral salts, particularly chloride ions, and is supplied to rock, masonry, and materials up to 300 miles from coastal waters (Wellman and Wilson 1965). Bursting bubbles of seawater form water droplets of aerosol size, and a further reduction in size is caused by the evaporation of the water droplets. $\mathrm{NaCl}$, the most common salt in the oceans, is carried as fine spray and settles on the ground or on the top of buildings, from where it moves upward and downward. $\mathrm{NaCl}$, as well as some $\mathrm{Mg}$ and $\mathrm{Ca}$ salts, can form white rims. A high salt content can accumulate over time through the deposition of salt spray. High winds blowing over salt lakes can also supply large quantities of $\mathrm{NaCl}$ to nearby areas.

Rainfall is the source of the high chloride content of groundwater and salt lakes in coastal regions. Rainfall chemistry varies with distance from the sea and in inland situations the importance of chloride is reduced relative to sulfates, nitrates, and carbonates. However, near coasts, sea salt is a major factor controlling rainwater chemistry. Fog water can also account for the deposition of a substantial amount of some ions, which provide a source of salts on rock surfaces.

Most rocks have a primary content of salt or of chemical elements that can form salts after they have been released from the crystal lattice of rock-forming minerals by chemical weathering. Rocks contain salts as their constituents or as entrapped materials in their pores. Chlorides, sulfates, nitrates, carbonates, and oxides of iron are the most common constituents. Sulfates are common after natural weathering of pyrite. Calcium is dissolved from carbonate rocks and tends to form calcium sulfate (gypsum) in polluted air. Sulfates of calcium, sodium, and magnesium are most common among soluble salts in rock (Linnow et al. 2006; Mamillian 1993). Some bedrock contains old evaporitic beds as connate salts trapped in the sediment or rock at the time of deposition. Leaching may transfer these evaporites to modern evaporite basins in which they may reproduce soluble salts. Some shale also contains appreciable quantities of salts; for instance, colliery shale waste is a source of sulfates and may contain $1-5 \%$ soluble salt, whereas pyretic shales are especially prone to producing gypsum.

Salt attack from deicing salts scattered on drives and sidewalks during winter to remove ice has caused more damage to adjacent stone than any other source by adding salts to the environment (Winkler and Singer 1972). Deicing salts are introduced to walls by water and also by wind in very cold weather. The saline solutions of
$\mathrm{NaCl}$, and more recently $\mathrm{CaCl}_{2}$, disaggregate and flake porous and semiporous stone and concrete on walls by crystallization pressure, leading to crumbling and spalling. The presence of these salts also increases chemical dissolution attack. $\mathrm{CaCl}_{2}$ is now more frequently used as it is more environmentally friendly, replacing persistent $\mathrm{Na}$ ions with $\mathrm{Ca}$ ions that are readily absorbed by plants.

Salts may come from Portland cement (Fassina 1994), which may contain up to $1 \%$ soluble alkalis. The ions leached out may form efflorescences of alkali carbonate salts, including trona (Charola and Lewin 1979).

Under some conditions, salts and acids may be produced biologically by a range of microorganisms through biochemical processes. Soils around areas of human activity are enriched in chlorides and nitrates because humans and animals deposit excrement and urine, which contain appreciable quantities of chlorides and nitrates, and microorganisms produce nitrates from excrement and waste (e.g., Hosono et al. 2006; La Russa et al. 2017; Přikryl et al. 2017; and Lubelli et al. 2018). Although nitrates originate from biological metabolism, there is no known biogenic source for the chlorides being concentrated in similar quantities in the same rising moisture zone. In addition, bacteria can oxidize ammonia to produce nitrate salts, whereas lichens living on calcareous rocks may secrete oxalic acid, which reacts with calcite to form calcium oxalate salts.

The use of incompatible materials for restoration and preservation can produce salts. The materials that cause salt weathering include acids, alkaline solutions, ionogenic tensides, Portland cement, waterglass products, and siliconates. Acids neutralized with alkaline solutions and vice versa produce salts. However, the most important deterioration is caused by salts from waterglass products and Portland cement (Zehender and Arnold 1989). Some stone chemical treatment, such as consolidants and sealants, release alkali metals during curing, especially sodium and potassium waterglasses. Sodium and potassium cations combine with sulfate, carbonate, and other anions to join the soluble salts traveling through the masonry. Because the salt types and moisture sources that aid salt weathering differ greatly, considering the diversity of salts and moisture sources can suggest under which environmental conditions salts are particularly effective weathering agents.

\subsection{Mechanisms of salt weathering}

The presence of soluble salts in porous materials is only harmful when there are changes in environmental conditions leading to crystallization-dissolution cycles. The problem is in explaining why and how salt damage occurs. The earliest hypothesis (Correns 1926; Correns and Steinborn 1939; Correns 1949) suggested that crystallization pressure was responsible for weathering via hydrostatic crystallization pressure and linear crystal growth pressure. Ten years later, their theory was completed by Weyl (1959) and Wellman 
and Wilson (1965) developed a thermodynamic model to calculate the crystallization pressure. The hydration pressure was first suggested by Mortensen (1933) and verified more recently (e.g., Kwaad 1970). There are other proposed mechanisms, and the interim model contributes to the understanding of the degradation of porous materials by salt. However, most models have not yet been verified by the laws of physics, chemistry, or physical chemistry (thermodynamics). Several equations of the theories are summarized in Table 1.

\subsection{Crystal growth pressure}

Crystallization of salt from supersaturated solutions can destroy rocks and other porous materials. This salt crystal growth is the most dangerous of the salt weathering processes, as it generally exerts a wedging force as the salt solution in rock pores and cracks crystallize (Steiger 2005a, 2005b; Genkinger \& Putnis 2007; Ruiz-Agudo et al. 2012; Scherer 2004, 1999, 2006). Because the tensile strength of rocks is in the range of one third to one tenth of their compressive strength, the pressure caused by crystallization and hydration of salts exceeds that of most rocks and concrete (Knacke and Erdberg 1975). This pressure is called crystallization pressure or crystal growth pressure and causes salt weathering in rocks, monuments, buildings, and other structures. The pressure is caused by the volume of the salt increasing against the confining force of the rock.

Early knowledge of salt weathering suggested that the mechanism of rock collapse was the total volume expansion of the salt-solvent system due to the crystallization of the supersaturated solution. This hydrostatic crystallization pressure occurs when the supersaturated solution occupies a smaller volume than the precipitated crystals and the residual saturated solution (Correns 1926). This pressure is directly proportional to the supersaturation ratio. However, as the pressure increases, according to Le Chatelier's principle, the solubility of the salt also increases, thereby reducing the supersaturation ratio. Therefore, this type of mechanism cannot account for the observed deterioration of porous stones by salts (Kwaad 1970; Duttlinger and Knöfel 1993).

Taber (1929, 1930; cited in Evans 1970) argued that water freezing or supercooling is similar to the crystallization of solutes in unsaturated materials. Freezing depends on intermolecular attraction rather than volume expansion, and molecules in solution reach the point of attachment to the growing crystal by osmotic pressure. However, this similarity is limited to salt crystallization involving salt and solvent. This is primarily because only salts, which are a relatively small proportion of the system, are converted to the solid phase, and secondly, crystallization of the salts involves a smaller volume expansion (Correns and Steinborn 1939). In contrast, as the water cools, freezing may begin from the top surface and the entire system eventually solidifies, thus creating pressure in the closed gap.

The crystallization of the salt by cooling can likewise apply pressure by the change in volume, but because the system is necessarily open, when salt crystallization by evaporation occurs, the pressure cannot be applied by the total volume change. That is, the holes must be large enough to allow easy communication with the atmosphere, and there must be a net loss of water content by evaporation. Furthermore, once the gap widens, it is almost impossible to cause rock disaggregation, as the entire volume change cannot exert any further destructive force.

Thompson (1862) pointed out that rock collapse is not caused by an expansion of the total volume, but by the growth of crystals in contact with a liquid that tends to deposit the same crystalline material on the solid, until the void space in which they are contained is filled. Cobb et al. (1990) also argued that the damage caused by the crystallization of sodium sulfate must be due to unknown crystallization forces, not volume expansion. Furthermore, Detsch (1914) showed that porous tiles and bricks can be destroyed as $\mathrm{Na}_{2} \mathrm{SO}_{3} \cdot 5 \mathrm{H}_{2} \mathrm{O}$ crystallizes with decreasing volume. Thus, the crystallization of the salt is not related to the volume expansion of the salt-solvent system but is related to crystal growth. So far, there have been few studies measuring crystal growth pressure.

Andree (1912) reviewed thoroughly on the subject and favored the views of Becker and Day (1916). Nonetheless, some researchers (e.g., Schbnikov 1935; Arakelyan 1987) failed to take into account the tendency of crystals growing against pressure to have concave undersurfaces, with the weight supported by a narrow rim and thus underestimated the crystallization pressure drastically by overestimating the area of contact between crystal and pore wall.

Becker and Day (1916) observed that if the solution was sufficiently saturated, the crystal could grow at points which were under pressure though stressed crystal growth was slower than the growth of unstressed crystals. The crystals not only grew on the top and sides but also grew a rim around the edges (but not below the central portion of the original crystal) of the bottom which lifted the growing crystals from its support. This lifting took place even if a substantial weight $(0.7 \mathrm{~g})$ was placed on the crystal but the rate of lifting was decreased by a factor of 25 over that of a crystal stressed only by its own weight. Becker and Day (1916) also remarked that the lifting force cannot be due to, as Bruhns and Mecklenburg (1913) suggested, capillarity, which would invoke surface tension pulling the crystal downward.

Taber (1916) confirmed that crystallizing alum, $\mathrm{CuSO}_{4}$ and $\mathrm{K}_{2} \mathrm{SO}_{4}$ could be able to lift glass plates several $\mathrm{mm}$ and the crystals exert a linear force regardless of which crystal face they rested on. The new growth was outward and downward, the original crystal sat at the top of a terraced hollow the depth of which equaled the height of 


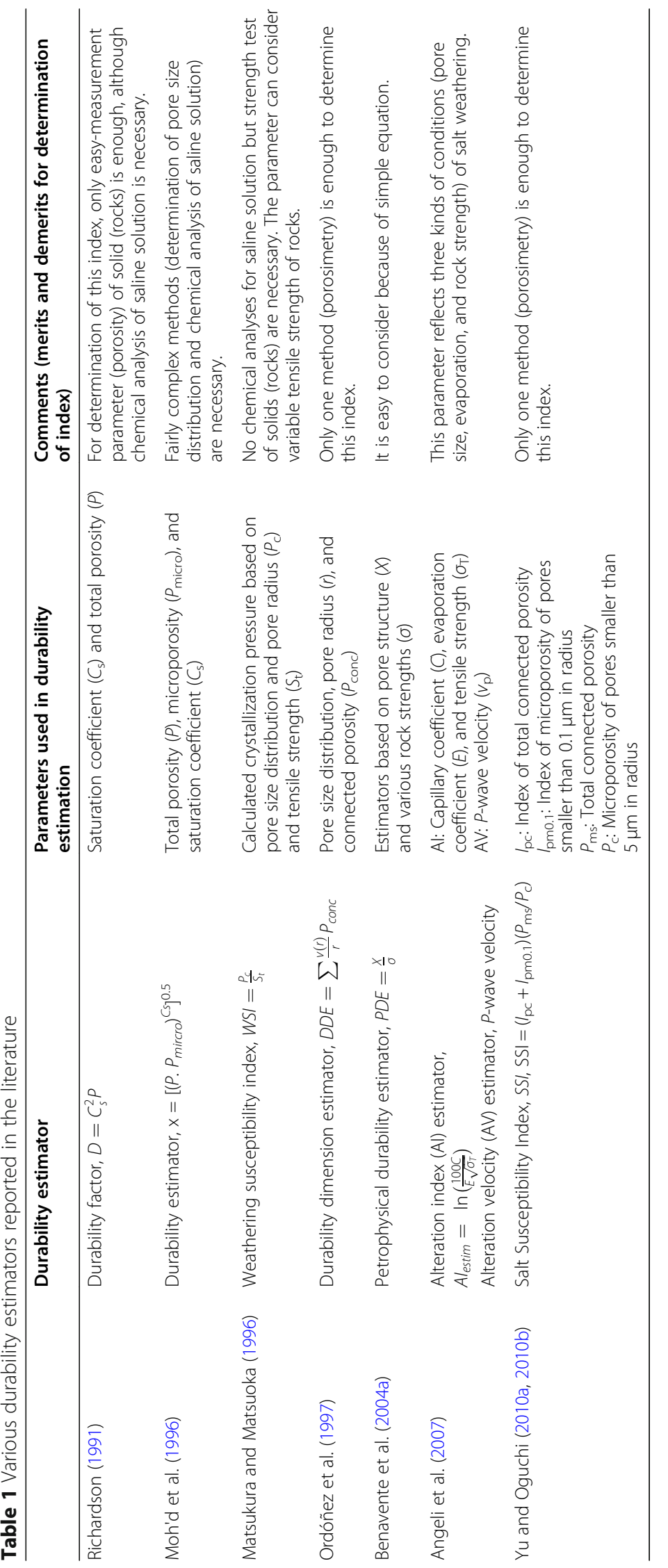


the lifting observed. He also came to similar conclusion with Becker and Day that growth of loaded crystals was naturally slower than that of unloaded crystals. However, the growth of the former could be increased by raising the level of supersaturation.

Mosebach (1951) measured pressures in excess of 47 atmospheres by growing copper sulfate $\left(\mathrm{CuSO}_{4} .5 \mathrm{H} 20\right)$ crystals. The author also showed that different crystal faces have different abilities to grow against pressure; the $(010)$ face of potassium chromate $\left(\mathrm{K}_{2} \mathrm{Cr}_{2} \mathrm{O}_{7}\right)$ could grow against a pressure more than twice the limit for the (001). Correns (1949) also found that certain faces of the alum crystal did not show any growth while others grew against pressures up to 42 atmospheres. An unsolved paradox is that surfaces parallel to the direction of pressure, with free access to the solution, ceased to grow at pressures much lower than for surfaces normal to the pressure.

\subsection{Influential theories, criticisms, and arguments}

The following three theoretical analyses are most influential and cited in the history of salt weathering research. The first is an early theoretical analysis of linear crystal growth pressure developed by Correns and Steinborn (1939). Correns (1949) analyzed the salt-solutionrock three-phase system based on the experimental observations of Taber (1916). For a thin supersaturated solution membrane, it is assumed that salt crystals in the confined pore space can grow while the film is maintained at the pore wall interface according to

$$
P_{\mathrm{c}}=\left(R T / V_{\mathrm{c}}\right) \ln \left(C / C_{\mathrm{s}}\right)
$$

where $P_{\mathrm{c}}$ is the pressure applied by crystal growth (atm), $R$ is the gas constant of the ideal gas law $\left(8.3145 \mathrm{~J} \mathrm{~mol}^{-1}\right.$ $\left.\mathrm{K}^{-1}\right), T$ is the temperature $(\mathrm{K}), V_{\mathrm{c}}$ is the molecular weight of the solid salt $\left(\mathrm{cm}^{3} \mathrm{~mol}^{-1}\right), C$ is the actual concentration of the solute during crystallization, and $C_{\mathrm{s}}$ is the saturation concentration of the solute. Much less research has been done on this theory after this formula was proposed (Wellman and Wilson 1965). Buckley (1951) also contributed a useful review of crystal growth pressure and recognized the existence of crystal growth potential.

The magnitude of the salt crystallization pressure is proportional to the degree of supersaturation of the salt solution. That is, it depends on the supersaturation ratio, $C / C_{\mathrm{s}}$; the higher the degree of supersaturation, the higher the pressure of the salt crystals, with limited space, to a lesser extent, and able to withstand temperatures inversely proportional to the molar volume of the salt present. This pressure depends on the type of salt and its hydrate. Due to the inverse relationship between crystal growth pressure and molar volume, salt hydrates exert lower crystallization pressures than anhydrous salts (Sperling and Cooke 1985).

Winkler and Singer (1972) and Winkler (1975) used the Correns equation to calculate the crystallization pressure of common salts at temperatures of 0 and $50^{\circ} \mathrm{C}$ as the supersaturation ratio increased to 2,10 and 50 . At $C / C_{\mathrm{s}}=10$, rock salt can exert maximum crystallization pressure of $2190 \mathrm{~atm}$. Rock salt crystals are mainly present in areas where high concentration ratios are caused by continuous evaporation, and transport of salt upwards can concentrate an almost unlimited amount of salt near the edge. A comprehensive review and discussion of crystal growth under these conditions was presented.

Duttlinger and Knöfel (1993) pointed out that the Correns equation is applicable only at low supersaturation ratios. That is, if the oversaturation value exceeds 1.3 , it deviates substantially from the theoretical value. They also showed that the crystallization pressure, frequently cited by Winkler (1975), was calculated from a highly unlikely supersaturation ratio in stone pore systems, and Amoroso and Fassina (1984) also discussed this topic. Cooke and Gibbs 1993demonstrated that $P_{\mathrm{c}}$ in the Correns equation is not necessarily the pressure exerted by crystal growth. They explain it as follows: "If supersaturation occurs in an unconstrained situation, crystallization will occur but no pressure will be applied. When the crystal begins to grow in a confined space in a porous solid, the volume change will make the solid elastically elastic. Stress builds up as it begins to deform, which increases as the deformation increases until it is relieved by plastic deformation (of ductile solids), cracking (of brittle solids such as stones), or the value of Pc. The issue with the Correns equation is that in the case of supersaturation, which can easily occur, $P_{\mathrm{c}}$ is very large and is probably not achieved before reaching the critical stress of internal cracks in porous stones. The internal stresses developed at the onset of cracking will then be directly proportional to the amount of crystallization that has taken place, the crystal molar volume $V_{\mathrm{c}}$ and the elastic moduli of the stone. It follows that the theoretical crystallization pressures $P_{\mathrm{c}}$ for various salts do not necessarily rank them in order of propensity for causing damage. So long as they all exceed the stresses required to cause internal cracking, the crystal characteristic that should be an indicator of damage propensity is the crystallization volume, $V_{\mathrm{c}}$. This accords with empirical observation."

Price (1978) also remarked that "How realistic is it to think that one can get significant degrees of supersaturation in a dirty piece of stone, with any number of possible nucleation sites? For example, won't the receding front of solution leave behind a supply of unstressed crystals that can act as nuclei?" 
Weyl (1959) is more sophisticated in including Correns' model for binary systems (mineral-solution-mineral) by considering that crystals can be grown by displacing solid constraints. In the proposed model, crystal growth exerts crystallization force against the restraint. Weyl's (1959) external stress causes crystals to dissolve. Pressure dissolution phenomena and crystallization forces are the result of the removal or deposition of mineral matter in the contact zone between mineral particles.

In the theory, under pressure dissolution and crystallization pressures, adjacent grains are separated by a film of solvent in which diffusion takes place up to an effective normal stress ( $\sigma=$ total normal stress - hydrostatic pressure). It is assumed that the pressures between grains will be very high. Weyl (1959) and Tada et al. (1987) found that the thickness of this solvent film must be of the order of a few molecules or a few nanometers for the diffusion of the solute to the deposition site to grow the stressed crystals. These solvent films are characterized by a diffusion constant, $D$, and thickness, $h$, which may depend on the effective normal stress, $\sigma$, across the film. $h$ decreases exponentially with $\sigma$, whereas $D$ does not change substantially throughout the film and the solute concentration is a linear function of the effective normal stress across the film.

As the normal stress exceeds the hydrostatic pressure, the solution film must be able to bear shear stress, and therefore cannot act mechanically as a liquid. To be active in solution or in precipitation, the solute ions must be able to diffuse into the film. The rate of diffusion through this film does not have to be as fast as in free solution, but it must be much faster than solid diffusion through adjacent mineral particles. Not all researchers define the solution film between crystals and pore walls supported by capillary forces as required for crystal growth and the resulting crystal growth pressure. Some researchers believe that close contact with the crystal wall is necessary (e.g., Weyl 1959).

Weyl (1959) provides different expressions to elucidate the processes of pressure solution and crystallization force. The contact surface across which the stress is transmitted is assumed to be a flat, circular plane and the change in effective normal stress $\sigma$ with distance $x(d \sigma / d x)$ is calculated from its center. If $d \sigma / d x$ is negative, that is, the effective normal stress increases inward toward the center of the area of contact, solute diffusion is outward to the less stressed areas and solute is removed from the zone of contact and hence pressure solution occurs. If $d \sigma / d x$ is positive, that is, the effective normal stress increases outward, inward diffusion may lead to continued deposition of solute from the solution film on the growing crystal surface at the contact area, and thus crystallization force is exerted against the stress.
If the average effective normal stress, $\sigma_{\text {avg }}$, at the margin of the zone of contact is positive (inward diffusion) and at the center is negative (outward diffusion), crystal growth takes place around the periphery and the crystal forms a hollow center, as in the experiments of Becker and Day (1916) and Taber (1916). As the average effective normal stress is increased, the rate of crystal growth decreases inversely to the stress and the radius of the hollow center shrinks until it disappears.

As the average effective normal stress increases further, the rate of crystal growth continues to decrease until the stress across the film is constant; hence, there are no more concentration gradients, and thus no diffusive transfer. Further increases in average effective normal stress changes the direction of solute diffusion, and pressure solution occurs at an increasing rate with the average effective normal stress until the film disappears and solution ceases. Therefore, Weyl's phenomenological theory could qualitatively confirm and elucidate the experimental results of Becker and Day (1916), who observed that alum crystals grew faster under low pressure than under high pressure.

Weyl's model is directly applicable to a threecomponent system (crystal-solution-rock) in which the relatively insoluble rock mineral differs from the solute, which crystallizes out. Weyl demonstrates that if the solution is supersaturated, precipitation in the area of contact between the crystal and the pore wall will occur as long as the ratio of the supersaturation, $\Delta_{\mathrm{c}}$, to the stress coefficient of solubility, $b$, is greater than the average effective normal stress, $\sigma_{\text {avg }}$, between the crystal and the pore wall. Hence, the force of crystallization occurs via crystal growth. A transition point will occur when the average effective normal stress becomes equal to the ratio of the supersaturation to the stress coefficient of solubility, and no more diffusion will occur at this point. After this transition, Weyl's mechanism indicates that crystallization will stop and pressure solution will take over if the average effective normal stress across the solution film exceeds the ratio of the supersaturation to the stress coefficient of solubility.

In deriving the theory, Weyl assumes that the minerals have a positive stress coefficient of solubility, that is, the minerals are more soluble under stress than without stress. If solubility increases with stress, crystallization can only occur at points of increased stress if the external solution is supersaturated. Therefore, minerals with smaller but positive fractional pressure coefficients of solubility can grow against higher stresses, or with lower supersaturation. Weyl gives the following practical example. Calcite has a fractional change of solubility with hydrostatic pressure of approximately $10^{-3}$ per atm (Owen and Brinkley 1941); therefore, at 1\% supersaturation, calcite should crystallize against an effective 
normal stress of $10 \mathrm{~atm}$. This is of the same order as the tensile strength of rock. If its supersaturation is higher, it will crystallize against a proportionately higher stress.

Although this assumption is valid for calcite and quartz, if a mineral has a negative pressure coefficient of solubility, the force of crystallization increases at points of stress and decreases solubility. Under this unstable system, needles would grow in the direction of maximum principal stress. However, all common natural salts crystallize with an increase in system volume and thus have positive pressure coefficients of solubility.

Weyl's model even shows that if supersaturation is sufficient, crystals can exert great pressure, without necessarily filling pores. This has also been experimentally verified by Becker and Day (1916) and Taber (1916). Even if crystals grow down capillaries, they can continue to grow in the pores that they fill. The pressure they exert is controlled by the local supersaturation, rather than by the size of capillaries.

In fact, Weyl considers Correns' model as an exceptional case. Although the surface tension, which indicates only whether the interstitial film exists, is necessary, it is only one of the conditions necessary for crystallization. It neither accounts for the continuance of lifting by crystallization from the film nor considers pressure solution by the film.

According to Evans (1970), Weyl's model is the only acceptable explanation for the observed force of crystallization (salt damage) and has been accepted as being more realistic and preferable to other approaches. Nevertheless, Yatsu (1988) felt Weyl's model was not entirely convincing because it assumes that the concentration of solute in the interstitial film is a linear function of the effective normal stress across the film, and the validity of this assumption has not been verified. In addition, Yatsu criticized the facts that no values were proposed for the stress coefficient of solubility, and that Weyl's model did not consider the potential energy during the crystallization from solution. However, data from Tada et al. (1987), Maliva and Siever (1988), and Dewers and Ortoleva (1990) validated Weyl's model and its ability to explain various natural phenomena.

The presence of a clay film in the solution film bordering the two crystal grains increases the force of crystallization. The clay film consists of a series of platelets with associated water films. These water films provide substantially increased rates of solute diffusion, which increase the rate of crystallization (Weyl 1959).

Wellman and Wilson (1965), who were inspired by the works of Everett (1961) and Lewis and Randall (1961), developed a thermodynamic model for calculating the crystallization pressure in a porous solid with large pores and small pores in contact with each other. Thermodynamically, there is chemical free energy associated with the surface of a crystal and because this free energy increases with its surface area, the area of its interfaces should be minimized to minimize the free energy of the crystal. Hence, in a system containing crystals in equilibrium with a saturated solution, larger crystals will grow at the expense of smaller crystals because smaller crystals have a higher free energy per unit mass than larger crystals owing to the higher surface-volume ratio for smaller crystals.

The work that must be done by crystal growth on one face of a crystal is equal to the pressure difference (atm) between the solid and liquid $\left(P_{1}-P_{\mathrm{s}}\right)$ multiplied by the increase in crystal volume, $d V\left(\mathrm{~cm}^{3}\right)$. This work must equal the work required to extend the surface, $\sigma d A$, where $\sigma$ is the interfacial tension between the solution and the growing crystal (dyne $\mathrm{cm}^{-2}$ ), and $d A$ is the increase in crystal surface area $\left(\mathrm{cm}^{2}\right)$. Because $\sigma$ is independent of $V$, the equation developed by Wellman and Wilson (1965) to calculate the pressure built up in this way is

$$
P_{1}-P_{\mathrm{s}}=\sigma d A / d V
$$

They inferred that crystallization induced by evaporation or a temperature change occurs in the larger pores initially, as supported by observations of Zehnder and Arnold (1989). The larger crystals in these large pores will grow at the expense of small crystals in the small pores, which supply solution to the large pores (Fig. 2). When the larger pores are completely filled, the crystals in these pores do not grow out into the smaller pores because this $\left(P_{1}-P_{\mathrm{s}}=\sigma d A / d V\right.$ for the crystals to grow down the capillary pores) requires a large increase in interfacial surface area relative to the small increase in volume, which would increase the chemical potential (free energy per mole or per gram of material) of the crystal extensions hugely.

Thus, the crystals continue to grow until they exert a pressure against the pore walls, which raises their chemical potential to that of the crystal extensions in unfilled pores, and this eventually disrupts the rock. Even when crystals form suddenly in all the pores, that is, there are larger crystals in larger pores and smaller crystals in tiny pores, the smaller crystals dissolve to decrease the free energy of the system and the ions are transferred to the larger crystals. Thus, the larger crystals continue growing until they exert the crystallization pressure on the pore wall.

Wellman and Wilson (1965) state that whether disintegration occurs depends on the smallness of the small pores (the smaller the pores, the greater the pressure the crystals can exert) and the value of $\sigma$ compared with the mechanical strength of the porous material. If the surface tension, $\sigma$, of the salt multiplied by $d A / d V$ of the 
micropores is greater than the mechanical strength of the rock, the large pores will be enlarged.

Wellman and Wilson (1965) proposed that the excess pressure caused by crystallization in a large pore, $\Delta P$ (dyne $\mathrm{cm}^{-2}$ ), derived from the modified Laplace equation, is equal to

$$
\Delta P=2 \sigma(1 / \mathrm{r}-1 / R)
$$

where $\sigma$ is the surface tension (dyne/cm) and $R$ is the radius of the large pore $(\mathrm{cm})$ connected by a capillary of radius $r(\mathrm{~cm})$. Thus, when the excess pressure exceeds the tensile strength of the rock, the material will fracture. The model predicts that crystallization will originate in larger pores, and for porous materials of equal mechanical strength, materials with large pores separated by areas of micropores will be most susceptible to disruption by salt crystallization (cf. Honeyborne and Harris 1958).

The Wellman and Wilson model is based on the theoretical freezing model developed by Everett (1961), who established that freezing results in the generation of capillary pressure by a solid growing at the expense of a liquid in a capillary. The thermodynamic background for this theory, according to Evans (1970), is valid only for fluid, such as gas-liquid and liquid-liquid interactions, and its extrapolation to solid-liquid interactions, though widely accepted, has not yet been validated. Evans (1970) criticized that $P_{1}-P_{\mathrm{s}}$ may be very large and yet causes pressure solution of the crystal so that the rock cannot be forced apart. Tiller (1991) also stated that the capillary pressure, which is valid for liquids, is a fictitious quantity when applied to solids.

Rodriguez-Navarro and Doehne (1999) argued that their experimental observations conflict with Wellman and Wilson's (1965) model but that they agreed with the original model for the generation of crystallization pressure proposed by Correns (1949) and completed by Weyl (1959). They reasoned that the Wellman and Wilson model does not include the capillary (suction) pressure $P$ (atm), which is, according to the Laplace and Washburn equation, inversely proportional to the pore radius,

$$
P=2 \sigma \cos \theta / r
$$

where $\sigma$ is the interfacial tension and $\theta$ is the contact angle of the meniscus at the pore wall of radius $r(\mathrm{~cm})$. This means that as evaporation progresses, the saturated solution is suctioned from the larger pores toward the smaller pores, where it is concentrated. Thus, once critical supersaturation is reached, crystallization occurs in the smaller pores, not in the larger ones. The larger pores act as reservoirs supplying solution to the smaller ones where high supersaturation ratios can be reached.
They refer to Tiller's (1991) observation that heterogeneous nucleation of a crystal occurs in the smallest pores, where the solution is withdrawn and eventually reaches high supersaturation ratios, thereby generating high crystallization pressures, according to Correns (1949).

However, the Wellman and Wilson model appears to be well accepted by many other researchers, such as Fitzner and Snethlage (1982), Zehnder and Arnold (1989), Rossi-Manaresi and Tucci (1991). Fitzner and Snethlage (1982) developed an equation that considers the crystallization pressures more explicitly in relation to porous materials. Following the work of Everett (1961), they approach the theoretical problem of crystallization pressures in porous media in terms of an analogy with the thermodynamics of freezing of solutions in porous materials.

Fitzner and Snethlage (1982) expressed the crystallization pressure as

$$
P=2 \sigma(1 / r R)
$$

where $P$ is the crystallization pressure, $\sigma$ is the ionic interfacial tension of the salt solution, $r$ is the radius of the small pores, and $R$ is the radius of the large pores.

According to this theoretical approach, crystallization occurs first in large pores and only moves into small pores once the larger ones are full. Until that point the small pores act as supply reservoirs for salt solutions. Thus, stones with a high volume of large pores and a higher volume of smaller pores are particularly sensitive to salt weathering and frost weathering.

Fitzner and Snethlage (1982) used their equation to calculate crystallization pressures for four German sandstones whose pore size distribution had been measured. The results showed that the pressure should increase uniformly with decreasing pore size, in contrast to differences in the actual behavior of the stones. Using pore geometry models, they developed multiplying factors $V_{1}$ and $V_{2}$ to correct the calculated crystallization pressures. The factor that gave the best results compared with the experimental crystallization results was

$$
V_{2}=V \mathrm{r} / \Sigma V R
$$

where $V_{\mathrm{r}}$ is the volume of pores of radius $r$ and $V R$ is the volume of pores of radius $R$. This factor does not have any thermodynamic significance, but it increases the importance of smaller pores. This approach could be useful in estimating the durability of a stone if the pore size distribution is known.

A similar approach was used by Rossi-Manaresi and Tucci (1991) to calculate the resistance to salt deterioration of three biocalcarenites, tuff, marble, and 
sandstone. Interestingly, they used the first correction factor, $V_{1}$, which is expressed as

$$
V_{1}=V \mathrm{r} / V R
$$

In the case of the German sandstones, $V_{1}$ did not match the experimental results. Rossi-Manaresi and Tucci (1991) did not compare the calculated values with the experimental results. Their calculations used changes of pore size distribution in different samples of the same material, such as the surface vs. interior. For example, the surface crust of sandstone had a higher number of smaller pores, and hence the higher crystallization pressures should lead to its flaking. The heterogeneity in pore size distribution of the calcarenites was predicted to produce an alveolar deterioration pattern. Finally, marble, which had few small pores, was predicted to be resistant to salt crystallization.

Aside from some controversy, crystallization generally continues even to considerable limiting forces. The crystal growth pressure in the pores causes local tension, which tends to crack the pores and propagate them by tensile failure. To allow the salt to crystallize, the solution film must be maintained at the salt-rock interface. The surface tension between the salt and the rock must be exceeded. Crystallization can continue from this membrane only if the solute diffuses in, which requires that the effective normal stress be reduced inward toward the center of the contact area. Because the solubility of the salt increases with pressure, crystallization can occur up to the pressure at the pressure rise point only if the solution retains its degree of supersaturation. Small supersaturations easily achieved by rapid evaporation or cooling can result in a wedging force of crystallization that exceeds the tensile strength of rocks, stones, and other porous building materials. However, for complete crystallization from a rock penetrating solution, several days of rainfall or strong evaporation without spray are required. Because evaporation generally occurs during heating, crystallization can increase thermal stress by exacerbating space problems.

Salt weathering research also focuses on pore structure and porous networks from various perspectives (Fitzner 1988; Angeli et al. 2008; Benavente et al. 2001, 2004b, 2007; Gomez-Heras \& Fort 2007; Yu \& Oguchi 2013; Kozlowski et al. 1990). Cardenes et al. (2013), Thomachot-Schneider et al. (2018), and Török and Szemerey-Kiss (2019) examined the relationship between freeze-thaw and salt crystallization. Raneri et al. (2015) used micro X-ray computed tomography $(\mu \mathrm{XCT})$ to understand the pore structure. Owing to advances in computing, $\mu \mathrm{XCT}$ is an important technique for rock weathering studies, although in the 1990s, it was impossible to distinguish pores in rocks due to poor resolution. Schiro et al. (2012) investigated the orientation of crystal propagation in the crystallization of $\mathrm{MgSO}_{4}$ and discussed the crystal growth that occurs inside the gap in detail. With these recent advances, a revised version of Winkler's theory has been published (Winkler 1994; Steiger et al. 2014).

\subsection{Hydration}

Some salt hydrates and anhydrates change easily at atmospheric temperature and $\mathrm{RH}$. Hydration can occur when the temperature is below the transition point of a particular salt. At the transition point, a reversible change occurs from anhydrous salt to hydrate, or lower hydrate to higher hydrate. The salt can be repeatedly hydrated and dehydrated in the pores as the amount of hydration water increases or decreases.

The famous German geomorphologist Mortensen (1933) first recognized the importance of salt hydration as a factor in desert weathering. In his pioneering dissertation, Mortensen challenged the then accepted view that the damage observed in desert rocks was caused by frozen water, a process similar to saltwater crystallization. Instead, he asserted that crystallization pressure does not occur because the crystals deposited from saturated solution by evaporation occupy less volume than the original solution. As the salt hydrates, the pressure decreases as the volume increases. He proposed that rising solutions caused by capillary action containing salts, such as $\mathrm{Na}_{2} \mathrm{SO}_{4}, \mathrm{Na}_{2} \mathrm{CO}_{3}, \mathrm{MgSO}_{4}$, and $\mathrm{CaSO}_{4}$, have no or low crystallization water during the daytime when the soil surface temperature is high, causing surface formation of crystals. When nighttime cooling to ambient environmental conditions occurs, these anhydrous salts or lower hydrates become more stable hydrates or achieve higher hydration by absorbing water vapor from the atmosphere to the crystal lattice. The volume expansion of the hydrated salt causes the hydration pressure on the pore wall.

To illustrate the point, Mortensen (1933) calculated the hydration pressures of salts typically found in deserts by the theoretically derived equation

$$
P=R T / V \ln \left(p_{1} / p_{2}\right)
$$

where $P$ is the hydration pressure (MPa or atm), $T$ is the absolute temperature (K), $V$ is the molar volume of water of crystallization $\left(\mathrm{cm}^{3} \mathrm{~mol}^{-1}\right.$ or $\left.\mathrm{mL}\right), R$ is the gas constant, $p_{1}$ is the vapor pressure of water at $T(\mathrm{mmHg})$, and $p_{2}$ is the dissociation vapor pressure of the hydrate at $T$ (mmHg). According to this equation, salt hydration pressure depends directly on the number of moles of water gained by a salt during hydration, on temperature, and on the ratio of the atmospheric vapor pressure to the dissociation vapor pressure of the salt-hydrate. Furthermore, the salt hydration pressure is inversely related to the volumetric expansion of the salt on hydration. 
As with crystallization, the ambient environmental conditions necessary for a salt to hydrate are complex. Even at low temperatures, the atmospheric aqueous vapor pressure must exceed the dissociation vapor pressure of the salt-hydrate system for hydration to happen. On the other hand, for a given atmospheric vapor pressure, the temperature, which controls the dissociation vapor pressure, should fall below a certain value for the transition to occur. Therefore, high RH accompanied by a fall in temperature are merely side effects, which do not account the formation of hydrates. In short, in addition to transition vapor pressures, some salts also have a transition temperature above which only the anhydrous form or a lower hydrate is stable. The effect of increasing external pressure on the dissociation vapor pressure has been considered. Depending on the pressure of the hydrate (Moore 1896), the formation of the hydrate against the confinement force can only proceed until the dissociation vapor pressure, which increases with the generation of the expansion pressure, is equal to the saturation vapor pressure of the free water.

Mortensen (1933) also observed that the transition temperature of sodium sulfate is $32.4{ }^{\circ} \mathrm{C}$ in pure solution and drops to $17.9^{\circ} \mathrm{C}$ in a sodium chloride saturated environment. Below $32.4^{\circ} \mathrm{C}$, the stable form of the anhydrous salt, $\mathrm{Na}_{2} \mathrm{SO}_{4}$, or the hydrate, $\mathrm{Na}_{2} \mathrm{SO}_{4} \cdot 10 \mathrm{H}_{2} \mathrm{O}$, depends on the vapor pressure. Furthermore, for some salts, the transfer may be rapid. At $39^{\circ} \mathrm{C}$, the transition from thenardite to mirabilite is complete within $20 \mathrm{~min}$. Hydration of $\mathrm{Na}_{2} \mathrm{SO}_{4}$ to its heptahydrate form at $31{ }^{\circ} \mathrm{C}$ and of $\mathrm{Na}_{2} \mathrm{CO}_{3}$ to its decahydrate form at $32.4{ }^{\circ} \mathrm{C}$ shows the presence of excess water $(>60 \%)$ Sodium sulfate underwent a volume change of more than $300 \%$ during hydration; however, at very low humidity, such as $30 \%$, hydration does not usually occur.

Mortensen's work is supported by Bonnell and Nottage (1939). They developed simple, robust molds under compression, changed the temperature, and measured volume changes for different mixtures of hydrated salts (sodium sulfate and magnesium sulfate) and sand. They revealed that anhydrous salts (or lower hydrates) can be hydrated (or further hydrated) to moderately high stress. Because these stresses far exceed the tensile strength of conventional porous building materials, when hydration occurs in the pores of such building materials, the salt would probably exert sufficient force during the hydration to causes the material to collapse. Bonnell and Nottage (1939) did not adapt unexpanded pores to the swelling expansion, and the salt crystals expanded to moderately high stresses regardless of whether they were completely constrained in one direction. Some salt crystals continue to grow even though the large pores in which the crystals can grow without stress are not filled.
Cooke and Smalley (1968) suggest that in addition to the crystal growth pressure, destructive stress can also be caused by the dehydrated salt at high temperatures in deserts. The presence of both anhydrite and gypsum in deserts suggests that some interconversion may occur, and the presence of other salts tends to promote the dehydration reaction.

Although Cooke and Smalley (1968) cite Detsch (1914), when they partially filled test tubes with plaster of Paris and water stucco, the test tube often broke due to apparent volume expansion. When bassanite turns into plaster, the volume increases by about $7 \%$. They theoretically predicted a volume reduction of $7 \%$ during the curing of pastes of $\mathrm{CaSO}_{4} \cdot 1 / 2 \mathrm{H}_{2} \mathrm{O}$ and $\mathrm{H}_{2} \mathrm{O}$, but in fact there was a $0.5 \%$ expansion. Thus, even partially dewatered salts are expected to exert forces on the walls of pores when they are hydrated. This effect damages construction materials (Schaffer 1932).

Various forms of hydrated and anhydrous $\mathrm{CaSO}_{4}$ are common in deserts, and the weathering mechanism of hydration-dehydration proposed by Cooke and Smalley (1968) is as follows: (1) Hydrated salts are deposited in rock cracks. (2) Dewatering aids salts under high temperatures in the desert, then subsequently rapid wetting and hydration occurs, and consequently, the wall of the fracture is stressed. However, according to Goudie and Viles (1997), this mechanism is not fully understood. In many cases, there should be room to expand again, as the anhydrous salt may be formed initially from the salt solution in the pore or from the hydrated salt.

Kwaad (1970) presents several conditions that must be met to allow the rock to collapse due to salt hydration. First, the process of hydration should be fast enough to be achieved largely within about $12 \mathrm{~h}$; otherwise, the hydration cannot be caused by the daily change of temperature. Second, to exert hydration pressure, the hydrated salt should not be able to escape from the hole where it exists. Third, the hydration pressure must exceed the tensile strength of the rock at the hydration point.

Winker and Wilhelm (1970) suggested that crystallization pressure against the pore walls is a one-off process, whereas the hydration pressure affects the crystalline salts and may change several times in a season or diurnal cycle. To calculate the pressures theoretically produced by hydration, Winkler and Wilhelm modified Mortensen's equation as

$$
P=\left[n R T /\left(V_{\mathrm{h}}-V_{\mathrm{a}}\right)\right] \times 2.3 \log \left(p_{\mathrm{w}} / p_{\mathrm{w}}^{\prime}\right)
$$

where $P$ is the hydration pressure (MPa or atm), $n$ is the number of moles of water gained during hydration to the next highest hydrate, $R$ is the gas constant, $T$ is the absolute temperature $(\mathrm{K}), V_{\mathrm{h}}$ is the volume of hydrate $\left(\mathrm{cm}^{3} / \mathrm{gm}\right.$ mol of hydrated salt), $V_{\mathrm{a}}$ is the volume of the 
original salt before hydration $\left(\mathrm{cm}^{3} / \mathrm{gm} \mathrm{mol}\right), p_{\mathrm{w}}$ is the vapor pressure of water at a given temperature $(\mathrm{mmHg})$, and $p^{\prime}{ }_{\mathrm{w}}$ is the vapor pressure of the hydrated salt (mmHg).

They calculated the hydration pressures of some important common salts (bassanite-gypsum, thenarditemirabilite, kieserite-hexahydrite, hexahydrite-epsomite, thermonatrite-heptahydrite, and heptahydrite-natron) at different temperatures and relative humidities by using the data on the dissociation vapor pressures of the hydrates from Mortensen (1933) and other chemical constants from Weast (1967). They observed that the greatest hydration pressures (maximum of $2190 \mathrm{~atm}$ at $0{ }^{\circ} \mathrm{C}$ and $100 \% \mathrm{RH}$ ) occur when bassanite is converted to gypsum. This is in excess of the crystallization pressure of ice at $-22{ }^{\circ} \mathrm{C}$ and is in excess of the pressure required to exceed the tensile strength of rocks.

Calcium sulfate hemihydrate (plaster of Paris), which occurs in nature as bassanite, is a key raw material in the building industry (Lager et al. 1984). Heating to 373-383 K produces a metastable anhydrite, which rehydrates rapidly under normal atmospheric conditions. The hydration pressure of anhydrite to gypsum causes a maximum pressure of $2800 \mathrm{~atm}(283.71 \mathrm{MPa})$ at $0{ }^{\circ} \mathrm{C}$ and $100 \%$ RH (Winkler 1975). The hydration of various magnesium sulfates is less common (Foster and Hoover 1963) and exerts only low pressures. The hydration of thenardite to mirabilite is fast and effective in salt weathering. In general, low temperatures and high RHs produce high hydration pressures, whereas high temperatures and low RHs produce low pressures.

The hydration pressures calculated by Winkler and Wilhelm (1970) have been quoted extensively in literature, although Evans (1970) pointed out that Winkler and Wilhelm (1970) do not discuss the extent to which the hydration pressures they have calculated can be realized in nature. He also argues that although their data show that the theoretical pressures increase with $\mathrm{RH}$ and with decreasing temperature, these pressures (2190 atm for $\mathrm{CaSO}_{4}$ ) have not yet been observed experimentally. Moreover, their calculated hydration pressures for the bassanite-gypsum system (hemihydrate to dihydrate) were shown to be inaccurate by Kirchner (1996), who also calculated the hydration pressures associated with the halite $(\mathrm{NaCl})$ and hydrohalite $\left(\mathrm{NaCl} \cdot 2 \mathrm{H}_{2} \mathrm{O}\right)$ system. In fact, Mortensen's hypothesis of hydration pressure appears logical and was not strongly questioned for more than 60 years because, as Duttlinger and Knöfel (1993) highlight, there have been few attempts to validate the hydration pressure theory experimentally under controlled conditions and results have been inconclusive.

Duttlinger and Knöfel (1993), in their thorough analysis of Mortensen's hypothesis, derived Eq. (9) above considering hydration as an osmotic process. When
Duttlinger and Knöfel (1993) rederived Eq. (9) from the sources mentioned by Mortensen, they obtained a slightly different equation that resulted in far smaller calculated pressures. Because osmotic processes require the presence of liquid water, Duttlinger and Knöfel concluded that the formation rate of the hydrate, via dissolution of the anhydrous salt and reprecipitation of the hydrate (Snethlage and Wendler 1997), must be a key factor. They suggested that the hydration rates of the individual salts could explain the observed differences in the effectiveness of the various salts in salt weathering.

Recrystallization does not always occur from one crystal lattice to another and may pass through the liquid state. For instance, anhydrite completely dissolves before it crystallizes as gypsum. The process is restricted to crystallization. Thus, there is no hydration pressure for the conversion of anhydrite to gypsum. Further studies on the hydration-dehydration mechanism of sodium sulfate also showed that while the dehydration of mirabilite proceeds via multiple dissolution steps ending in a polycrystalline mass of submicron particles, the hydration rate of anhydrous thenardite is slowed due to the formation of a hydrated film on the crystal surface (Charola and Weber 1992; Doehne 1994). That is, the hydration of thenardite does not proceed via absorption of moisture by a solid crystal but only by dissolution of that crystal and reprecipitation from solution.

Although the processes of crystallization and hydration have been recognized for many years, it is still difficult to differentiate the mechanisms despite a sound basis of theoretical understanding. However, it has long been accepted that the combination of crystallization and hydration appears to play an important role in salt weathering. For instance, McIntyre \& McTaggart (1979) concluded that hydration was important because the crystallization experiments showed that sodium sulfate was more effective in salt weathering than nonhydrating potassium sulfate. Winkler and Singer (1972) reported that the rate and role of hydration of rapidly hydrating $\mathrm{MgSO}_{4}$ inflicted $35 \%$ more damage than $\mathrm{Na}_{2} \mathrm{SO}_{4}$ during crystallization cycles.

Nevertheless, in considering the individual mechanisms, there have been many arguments relating to the effectiveness and importance of crystallization and hydration processes. Wilhelmy (1958) argued that although the force of crystal growth is real, it is rarely important in deserts because it involves crystallization from an oversaturated solution. He preferred Mortensen's mechanism of salt damage because repeated hydration alternating with dehydration is more realistic as the rock is alternately wetted and dried. However, Baker et al. (1968) noted that granulation by salts also occurs in regions of temperature and humidity where a transition point cannot be reached and suggested that these 
phenomena are better explained by the pressure of crystal growth.

Evans (1970) suggested that rocks may be shattered not only by the hydration of the salts in the rocks, but also by the initial process of crystallization. He contended that the crystallization process is more firmly based upon experiment and theory than the hydration process. He also argued that hydration is probably important for carbonates and sulfates because rock disintegration is often associated with gypsum. However, he did not explain the larger number of cases where sodium chloride, a non-hydratable salt, is the main salt associated with disintegrating rock. Moreover, Lewin (1982) proved that nonhydratable sodium chloride can disintegrate sandstone samples by crystallization pressure alone.

However, we note that sodium chloride can hydrate under very cool conditions as hydrohalite ( $\mathrm{NaCl} \cdot 1 /$ $2 \mathrm{H}_{2} \mathrm{O}$ ) and is stable at and below $0{ }^{\circ} \mathrm{C}$ (Johnston 1973). In addition, halite forms a dihydrate $\left(\mathrm{NaCl} \cdot 2 \mathrm{H}_{2} 0\right)$ at temperatures below $-0.1^{\circ} \mathrm{C}$, and it has been suggested that the effectiveness of sodium chloride as a weathering agent at subzero temperatures may, in part at least, be associated with the formation of this dihydrate (Williams and Robinson 1981, 2001).

Although it is not easy to separate the relative powers of hydration and crystallization (Sperling and Cooke 1980a), many laboratory experiments have been performed to try to determine whether the effectiveness of hydratable salts as a deterioration agent arises from hydration or crystallization pressure (Kwaad 1970; Chatterji et al. 1989; Sperling and Cooke 1985, 1980a). It has been shown that rock disintegration is possible by salt crystallization weathering alone under nonhydratable conditions or without hydration pressure. For example, Kwaad (1970) observed that $\mathrm{MgSO}_{4}$ and $\mathrm{Na}_{2} \mathrm{CO}_{3}$, which can hydrate during the diurnal temperature cycle, were less effective than $\mathrm{Na}_{2} \mathrm{SO}_{4}$, which hydrated too slowly and did not absorb any water of crystallization during the $12 \mathrm{~h}$ period of observation. He inferred from his experimental observations that $\mathrm{NaCl}$ stayed within the terms of the theory of crystal growth because the amounts of debris produced in the hydration tests and crystallization tests were similar. Kwaad (1970) also accepted the theory of crystal growth as valid for $\mathrm{Na}_{2} \mathrm{SO}_{4}$ because $\mathrm{Na}_{2} \mathrm{SO}_{4}$ exceeded the limits of Mortensen's hydration theory by being active even when no hydrate could occur and because its hydration velocity was low. On the other hand, other experimental work has established that hydration alone can be effective in rock disruption (Sperling and Cooke 1980b). Therefore, the arguments continue and this matter still needs to be scrutinized in further investigations.

Scherer (1995) claimed that the pressure exerted by salt hydration is doubtful and the statements about the hydration of crystals in most of the literature may be misleading. Scherer argued that crystals cannot absorb water and swell like a sponge because the crystal structures of the anhydrate and hydrated forms are entirely different, and therefore the crystal must dissolve and reprecipitate as the new phase. This is true for all crystals; hence, it is unlikely that rock disruption is caused by the hydration pressure of salt crystals. Rather, it is probably caused by the crystallization pressure during the growth of the new crystal phase.

Despite numerous experiments and observations of the process of salt weathering due to the hydration of various salts (Kwaad 1970; Steiger et al. 2008; Goudie 1977; Cooke 1979; Williams and Robinson 1981; Hamilton \& Hall 2008; Steiger \& Asmussen 2008; Stergonetch 2008), the nature of weathering processes by hydration require further study. Experiments must be conducted with greater precision to verify the theoretical values of hydration pressure to evaluate accurately the effectiveness of crystal growth pressures and hydration pressures of various salts (Yatsu 1988).

\subsection{Differential thermal expansion}

A further mechanism whereby salt attack may disrupt rock was proposed by Cooke and Smalley (1968). Though they accept the effectiveness of crystallization pressures, they argue that rock may also be disrupted by stresses caused by hydration of certain salts in confined spaces and stresses exerted by the thermal expansion of many salts in confined spaces. Therefore, the principal processes of salt weathering include crystal growth from solution, volume expansion accompanying hydration, and volumetric expansion of crystalline salts caused by temperature change (Cooke and Smalley 1968).

If strong surface heating-cooling occurs, the expansion of certain salts in the pores may be much greater than that of the rock, leading to thermal disruption, because the salts have higher coefficients of volumetric expansion than the minerals in the rock, thereby creating pressures sufficient to cause rock disintegration (Cooke and Smalley 1968). The extent to which salts expand when they are heated depends on their thermal characteristics and the temperature ranges to which they may be subjected. Hanus \& Luis (1968) also proposed the thermal expansion of crystalline salts.

Field and laboratory experiments have suggested that the expansion and contraction of rock minerals as a result of daily temperature changes in deserts are inadequate by themselves to cause disintegration (Griggs 1936; Parkus 1959; Möller 1990). Griggs (1936) proved that differential thermal expansion of rock minerals alone cannot account for rock burst in deserts. For a common desert salt like $\mathrm{NaCl}$, a typical temperature change of $54^{\circ} \mathrm{C}$ can produce a volumetric expansion of approximately $1 \%$, which is considerably greater than the expansion that would be expected in the 
surrounding rock. Halite, gypsum potassium chloride, barium sulfate, and sodium nitrate are common desert salts that have a greater expansion potential than rock minerals. The volumetric expansions of sodium nitrate, halite, and potassium chloride are more than three times that of granite, and sodium nitrate is likely to be the most effective of these salts (Cooke and Smalley 1968).

Many salts obscure this process of thermal expansion with crystallization and hydration, except for nonhydrating salts, such as halite, which do not usually exert hydration pressure. The thermal expansion with temperature increase from freezing to $60{ }^{\circ} \mathrm{C}$ is $0.5 \%$ for halite, whereas it is less than $0.2 \%$ for granite. This difference appears small, yet the disruptive expansion of salts can participate in rock decay. Therefore, if the rock is granite or another rock with similar properties, the effect of temperature changes on salts precipitated from solution in crevices and pores in these rocks near the surface may be considerable. First, large internal stresses are produced by crystallization, and then the combination of these internal stresses with the stresses caused by salt expansion may cause fracturing. The cracking produced by salt expansion in turn provides avenues for the further penetration of saline solutions, and the process may continue until the rock disintegrates (Cooke and Smalley 1968).

Cooke et al. (1993) argue that empirical studies of cliff weathering by Johannessen et al. (1982) support the effectiveness of the differential thermal expansion process. They showed that in the mid-latitude coastal environment of Oregon, the rate of cliff weathering was at least 10 times faster on sunny south-facing cliffs than on shaded north-facing cliffs. This contrast is attributed to the thermal expansion of $\mathrm{NaCl}$ on heating in the spray zone on the south-facing cliffs. The most important factor is probably the absolute range of temperature differences.

Cooke (1979) deduced the relative effectiveness of the three most cited salt weathering mechanisms as follows: "Crystal growth seems to be most pronounced where relatively saline solutions are rapidly evaporated, e.g., humid coastal deserts; hydration is probably most significant where diurnal changes of temperature and relative humidity combine to cause hydration thresholds to be crossed frequently; and thermal expansion of crystalline salts should be greatest where diurnal temperature changes are highest". Evans (1970) remarked that it is necessary to test experimentally whether the greater differential expansions introduced by salts are adequate. $\mathrm{He}$ argued that any such effect would be additive to that of crystal growth, which produces its greatest pressures as the rock dries because when all the solution has evaporated, the dry rock surface heats rapidly. Goudie (1974) maintained that the thermal expansion mechanism is possible only theoretically and proved experimentally that thermal expansion of salts is ineffective in rock disintegration along with insolation and wetting and drying processes. In fact, the importance of pressures due to the thermal expansion mechanism has not been investigated in any detail, and much more work is required to verify the existence and degree of effectiveness of this mechanism (Goudie 1974; Obika et al. 1989).

\subsection{Development of new theory from current research}

Lubelli et al. (2018) stated that new analytical methods and the categorization of degradation advanced. Certainly, as in Kamh et al. (2019), the categorization of the degree of deterioration is shown as an example by using formula previously proposed so far. In addition, research on the subdivision of the weathered layer has been reported due to advances in microanalysis technology (Přikryl et al. 2017). Furthermore, although it is a special environment like cave, there are also studies that investigated the relationship with environmental changes using isotopes (Gázquez et al. 2018).

Espinosa-Marzal and Scherer (2010) pointed out rather in detail the relationships between pore size and crystallization stress generation. They elucidated that the presence of small pores, equilibrium thermodynamics indicates that crystallization pressure can result from the curvature dependence of the solubility of a salt crystal, whereas non-equilibrium conditions, high transient stresses can occur even in larger pores.

Flatt 2002, 2003, Flatt \& Scherer 2002, Flatt et al. 2006 carried out extensive works on crystallization mechanisms. Flatt et al. (2017) summarized the formula for crystallization pressure as a supplementary technical paper. The idea of thermodynamics is introduced; firstly, the phenomenon of dissolution was explained and then it was replaced with the ion activity product. If stress is not generated from the crystallization pressure, the material will not break. There is a continuing movement to seek as much rock properties as possible to determine the stress generated.

There is also a study comparing the physical properties from accelerated experiments using salt solutions (e.g., Qiang and Zhang 2019; Dassow et al. 2020). Such properties of rocks are also examined by using sampled rocks in fields as well (Germinario and Ákos 2019).

Rock property change is one of the comparing measures of rock durability. Although not from a viewpoint of salt weathering but general weathering, Oguchi et al. (1999) indicated that the mechanical strength declined first among various properties which means that mechanical property is the most sensitive to weathering. Considering that mechanical strength is the most important parameter for construction planning, it may be the most important for targeting to prevent strength reduction. In 
other words, the structure will not collapse, if the strength can be prevented from decreasing, even though weathering or deterioration occur severely. From this point of view, the ideas and applications of surface protective agents are increasing (e.g., Manohara et al. 2019).

Research on micro- to meso-scale landforms such as honeycomb structure or taphoni has also derived from salt weathering. These kinds of studies are increased not only in geomorphological journals but also in material science journals (e.g., Chen et al. 2019; Li et al. 2019).

It can be said that this kind of study was originally dealt in geomorphology field but needs the sense of geochemistry or crystallography fields. Besides, review papers dealing with influence of risks of recent disasters and environmental problems have been appeared as well (McCabe et al. 2013; Gomez-Heras and McCabe 2015; Menéndez 2018; Bertolin 2019; Fusade et al. 2019). These multidisciplinary studies are welcome, although it might be difficult for many people to understand thoroughly. These multidisciplinary studies are welcome, although it might be difficult for many people to understand thoroughly. This is because it is necessary to deal with global warming and the intensification of disasters, which are becoming more serious year by year. Fluctuations in temperature and humidity will affect the type of precipitated salt.

Doehne and Price (2010) implied that new challenges in the future require materials for applied research, technology transfer, and long-term maintenance concerning more than 800 documents. Applied research and technology transfer are good at engineering and civil engineering, and their theory depends largely on the results of physics and chemistry. The present paper agrees with their statement, and the following viewpoints are dared to be added.

The change and alteration of a material can be considered as water-rock reaction, in detail, a solid-solution or a solidgas reaction, in which the material is placed as a deciding factor. Weathering and alteration of materials can be considered as water-rock reactions (WRI), in detail, solid-solution reactions or solid-gas reactions. In these cases, material location is one of controlling factors. If this concept applies to the weathering of a stone building, material is stone, and the location of the building represents environmental factors: temperature, RH, etc. Thus, it is necessary to consider how to suppress the reaction caused by the intrusion of water.

Regarding long-term weathering of durability, there is an example concept from geomorphology proposed by Suzuki (2002), called geomorphological equation: $Q=f(S$, $A, R, t)$, here, $Q$ is geomorphic quantity; $S$, geomorphic setting or initial landforms; $A$, geomorphic agent; $R$, resistance of landform materials; and $t$, duration of the acting agents. This concept simply means that landform changes can be estimated from above parameters in which particularly important parameters of material properties, time and environment of the location.
Applying this equation to stone weathering, the equation, $Q_{\mathrm{sw}}=f\left(S_{\mathrm{sw}}, A_{\mathrm{sw}}, R_{\mathrm{sw}}, t_{\mathrm{sw}}\right)$, will be expressed. Here, $Q_{\text {sw }}$ regards as weathering degree such as the amount removed or destroyed by weathering; $S_{\mathrm{sw}}$ is environmental condition, i.e., temperature, humidity, atmospheric, and pressure; $A_{\mathrm{sw}}$ is salt crystallization pressure or hydration pressure; $R_{\mathrm{sw}}$ is the resistance of rocks, not only rock strength but also pore characteristics; and $t_{\mathrm{sw}}$ is experimental duration or observing time.

In the viewpoint of microscale, the reaction processes may be divided by several steps. First, the surface reaction process such as dissolution will occur in a very thin layer. The dissolved chemical species will react with ion in solution. Then, solution concentration reaches to the solubility and excess saturation point of the compounds, precipitation or crystallization will occur. The pressure caused by the crystallization becomes higher than the rock strength, especially tensile strength, the rock will destroy. Thus, the parameters of $A_{\mathrm{sw}}$ and $R_{\mathrm{sw}}$ in the equation of $Q_{\mathrm{sw}}=f\left(S_{\mathrm{sw}}, A_{\mathrm{sw}}, R_{\mathrm{sw}}, t_{\mathrm{sw}}\right)$ is considered to have the own another equation. Furthermore, the thermodynamics express higher-level concept by itself of the $A_{\text {sw }}$ parameter. By composing all such equations and parameters, a practical equation for salt weathering can be proposed in the future.

Measures for estimating time $t_{\mathrm{sw}}$ are also being considered, especially from an archeological or geoscientific perspective to address long-term weathering and deterioration problems, for example, estimating the rate of development of a very thin weathered layer (altered layer) on the surface of a rock (Oguchi 2004). The estimated values are not high accuracy; however, it may be possible to estimate a certain amount of time as the time that the stone material was exposed to the environment for a long time. Collecting such information is an important approach to long-term problems. The recent studies from geochemistry and geomorphology can provide a breakthrough for this difficult estimation by using LAICP-MS or cosmogenic exposure ages (e.g., Yokoyama et al. 2018; Matsuoka et al. 2013).

By obtaining the rough theory relating to long-term changes are from geomorphology and archeological fields and by comparing to the fundamental theory from material science and thermodynamics, it may apply to more practical problems as a future perspective. Good cooperation in all these research fields will lead to meaningful conservation and utilization, even though it might take a long time. In the next stage of salt weathering research and reviews, it is somehow necessary to organize and consider these kinds of concepts.

\section{Concluding remarks-as a perspective}

The concept of crystallization including crystallization pressure as an important mechanism was first proposed 
in the early twentieth century. Many equations have been proposed and to apply them correctly, it is necessary to consider what type of salt weathering is observed. Thus, it is important to select and to apply the models proposed depending on the situation although it is necessary to consider the weathering environment as well as the types and properties of salts and rocks in salt weathering studies. A procedure to collect and rebuild information on these peripheral fields will also be necessary. Appropriate cooperation in all these research fields will lead to meaningful conservation and utilization will apply to more practical problems as a future perspective.

\begin{abstract}
Abbreviations
$P_{c}:$ The pressure applied by crystal growth (atm); $R$ : Gas constant of the ideal gas law $\left(8.3145 \mathrm{~J} \mathrm{~mol}^{-1} \mathrm{~K}^{-1}\right) ; T$ : Temperature $(\mathrm{K}) ; V_{c}$ : Molecular weight of the solid salt $\left(\mathrm{cm}^{3} \mathrm{~mol}^{-1}\right) ; \mathrm{C}$ : Actual concentration of the solute during crystallization; $C_{s}$ : Saturation concentration of the solute; $P_{1}$ : Pressure of liquid $P_{\mathrm{s}}$ : Pressure of solid; $V: C r y s t a l$ volume $\left(\mathrm{cm}^{3}\right)$; $\sigma$ : Interfacial tension between the solution and the growing crystal (dyne $\left.\mathrm{cm}^{-2}\right)$; A: Surface area $\left(\mathrm{cm}^{2}\right)$; ERH: Equilibrium relative humidity; $\mathrm{NaCl}$ : Sodium chloride (halite); $\mathrm{NaCO}_{3}$ : Sodium carbonate (natron); $\mathrm{Na}_{2} \mathrm{SO}_{4}$ : Sodium sulfate (thenardite); RH: Relative humidity; WRI: Water-rock interaction; $Q_{\text {sw: }}$ Weathering degree; $S_{\text {sw: }}$ : Environmental condition; $A_{\text {sw }}$ : Salt crystallization pressure or hydration pressure; $R_{\text {sw: }}$ : Resistance of rocks; $t_{\text {sw: }}$ : Experimental duration or observing time
\end{abstract}

\section{Acknowledgements}

The authors are grateful to research funds provided by JSPS KAKENHI (grant numbers 26350399 and 22000321).

\section{Authors' contributions}

CTO proposed the idea for this review and contributed some of the literature. Swe Yu collected the rest of the literature and drafted the manuscript. CTO approved the final manuscript. The authors read and approved the final manuscript.

\section{Authors' information}

CTO is an associate professor at Saitama University, and a member of the Geosphere System Research Group, which works on chemical and physical property analyses of various rocks for elucidating weathering processes that occur in both natural landscapes and cultural properties, especially building stones. Swe Yu was a PhD student who worked on salt weathering experiments, but he left his research activities and became a civil engineer to develop his home country. This review is based on his early career review works.

\section{Funding}

Not applicable.

\section{Availability of data and materials}

This article is distributed under the terms of the Creative Commons Attribution 4.0 International License (http://creativecommons.org/licenses/ by/4.0/), which permits unrestricted use, distribution, and reproduction in any medium, provided you give appropriate credit to the original author(s) and the source, provide a link to the Creative Commons license, and indicate if changes were made.

\section{Declaration}

\section{Competing interests}

The authors declare no competing interests.

\section{Author details}

'Graduate School of Science and Engineering, Saitama University, Shimo-Okubo 255, Sakura-ku, Saitama 338-8570, Japan. ${ }^{2}$ Present address: ST\&T Architect, Yangon, Myanmar.
Received: 1 November 2019 Accepted: 11 February 2021

Published online: 07 May 2021

\section{References}

Alves C, Figueiredo C, Ilharco LM, Fidalgo A, Maurício A, Aires-Barros L (2013) Specific surface area and salt weathering of limestones: a laboratory study. Q J Eng Geol Hydrogeol 46:477-484. https://doi.org/10.1144/qjegh2012-044

Alves C, Figueiredo C, Maurício A, Braga MAS, Aires-Barros L (2011) Limestones under salt decay tests: assessment of pore network-dependent durability predictors. Environ Earth Sci 63:1511-1527

Amoroso GG, Fassina V (1984) Stone decay and conservation: atmospheric pollution, cleaning, consolidation and protection. Elsevier Science Publishers, Amsterdam

Andree R (1912) To Boas. 1912 Jan. 14. https://diglib.amphilsoc.org/islandora/ object/andree-richard\%3A-boas-1912-jan-14\#page/2/mode/2up

Angeli M, Bigas JP, Benavente D, Menéndez B, Hébert R, David C (2007) Salt crystallization in pores: quantification and estimation of damage. Environ Geol 52:205-213

Angeli M, Bigas JP, Benavente D, Menéndez B, Hébert R, David C (2008) Modification of the porous network by salt crystallization in experimentally weathered sedimentary stones. Mater Struct 41:1091-1108

Arakelyan VS (1987) Effect of ultrasound on crystal growth from melt and solution. Acta Physica Hungarica 61: 185-187.

Arnold A (1982) Rising damp and saline minerals, 4th Int. Congr. Deterior. Preserv, Stone Objects, Louisville, Kentucky, 11-28.

Baker CL, Narberth, Holloway PW (1968) Sodium metasilicate pentahydrate product and preparation, United States Patent Office. 3377134.

Beaumont P (1968) Salt weathering on the margin of the Great Kavir, Iran. Geol Soc Am Bull 79:1683-1684

Becker GF, Day AL (1905) The linear force of growing crystals. Washington: Proceedings of the Washington Academy of Sciences VIl; pp 283-288

Becker GF, Day AL (1916) Note on the linear force of growing crystals. J Geol 4: 313-333

Benavente D (2011) Why pore size is important in the deterioration of porous stones used in the built heritage. Macla 15:41-42

Benavente D, Cueto N, Martínez-Martínez J, García del Cura MA, Cañaveras JC (2007) The influence of petrophysical properties on the salt weathering of porous building rocks. Environ Geol 52:215-224

Benavente D, García del Cura MA, Bernabéu A, Ordóñez S (2001) Quantification of salt weathering in porous stones using an experimental continuous partial immersion method. Eng Geol 59:313-325

Benavente D, García del Cura MA, Fort R, Ordóñez S (2004a) Durability estimation of porous building stones from pore structure and strength. Eng Geol 74: 113-127

Benavente D, García del Cura MA, García-Guinea J, Sánchez-Moral S, Ordóñez S (2004b) The role of pore structure in salt crystallization in unsaturated porous stone. J Cryst Growth 260:532-544

Bertolin C (2019) Preservation of cultural heritage and resources threathened by climate change. Geosciences 9:250. https://doi.org/10.3390/ geosciences 9060250

Birot P (1954) Désagrégation des roches cristallines sous l'action des sels. Comptes Rendus l'Acad Sci Paris 28:1145-1146

Bonnell DGR, Nottage ME (1939) Studies in porous materials with special reference to building materials, I. The crystallisation of salts in porous materials. J Soc Chem Industry 58:16-21

Bradly WC, Hutton JT, Twidale CR (1978) Role of salts in development of granitic tafoni, south-eastern Australia. J Geol 86:647-654

Bruhns W, Mecklenburg W (1913) Über die sogennante Kristallisationskraft, Jahresberichit des Niedersächsischen geologischen Verins zu Hannover VI, vol 92

Cammuffo D (1988) Microclimate for cultural heritage. Microclimate for Cultural heritage, Developments in Atmospheric Science 23. Amsterdam: Elsevier;

Cammuffo D, Delmonte M, Sabbioni C (1983) Origin and growth mechanisms of the sulfated crusts on urban limestone. Water Air Soil Poll 19:351-359

Cardell C, Rivas T, Mosquera MJ, Birginie JM, Moropoulou A, Prieto B, Silva B, Van Grieken R (2003) Patterns of damage in igneous and sedimentary rocks under conditions simulating sea-salt weathering. Earth Surf Process Landf 28: $1-14$

Cardenes V, Mateos FJ, Fernández-Lorenzo S (2013) Analysis of the correlations between freeze-thaw and salt crystallization tests. Environ Earth Sci 71:1123-1134 
Chapman RW (1980) Salt weathering by sodium chloride in the Saudi Arabian Desert. American Journal of Science 280:116-129

Charola AE, Lewin SZ (1979) Effluorescences on building stones-SEM in the characterisation and elucidation of the mechanisms of formation. Scanning Electron Microscopy. pp. 379-386.

Charola AE, Weber J (1992) The hydration-dehydration mechanism of sodium sulphate. In: Rodrigues JD (ed) 7th International Congress on the Deterioration and Conservation of Stone. Laboratorio Nacional de Engenharia Civil, Lisbon, pp 581-590

Chatterji S. Jensen AD (1989) Efflorescence and breakdown of building materials. Nordic Concrete Research 8:56-61.

Chen L, Guo F, Liu F, Xu H, Ding T, Liu X (2019) Origin of tafoni in the late Cretaceous aeolian sandstones, Danxiashan UNESCO global geopark, south Chana. Acta Geol Sin 93:451-463. https://doi.org/10.1111/1755-6724.13810

Clark BC (1998) Surviving the limits to life at the surface of Mars. J Geophys Res 103:28545-28555

Clark BC, Van Hart DC (1981) The salts of Mars, Icarus 45:370-378

Cobb KA, Dolnik V, Novotny M (1990) Electrophoretic separations of proteins in capillaries with hydrolytically-stable surface structures. Anal. Chem 62:2478

Cooke RU (1979) Laboratory simulation of salt weathering processes in arid environments. Earth Surf Process 4:347-359

Cooke RU (1994) Salt weathering and the urban water table in deserts. In: Robinson DA, Williams RBG (eds) Rock weathering and landform evolution. Wiley, Chichester, pp 193-205

Cooke RU, Brunsdenm D, Doornkamp JC, Jones DKC (1982) Urban geomorphology in drylands. Oxford University Press, Oxford

Cooke RU, Gibbs GB (1993) Crumbling heritage? studies of stone weathering in polluted atmospheres. Atmos Environ 28:1355-1356

Cooke RU, Smalley IJ (1968) Salt weathering in deserts. Nature 220:1226-1227

Cooke RU, Warren A, Goudie A (1993) Desert geomorphology. UCL. Press, London

Correns CW (1926) Über die erklärung der sogennanten kristallisationskraft. Berichte Preussischen Akad Wissenschaft 11:81-88

Correns CW (1949) Growth and dissolution of crystals under linear pressure. Discuss Faraday Soc 5:267-271

Correns CW, Steinborn W (1939) Experimente zur messung und erklärung der sogennanten kristallisationskraft. Z Krist 101:117-133

Coussy O (2006) Deformation and stress from in-pore drying-induced crystallization of salt. J Mech Phys Solid 54:1517-1547

Dassow J, Li X, Lee MR, Young M, Harkness P (2020) Ultrasonic drilling for the characterisation of building stones and salt induced decay. Ultrasonics 101: 106018. https://doi.org/10.1016/j.ultras.2019.106018

De Kock T, Turmel A, Fronteau G, Cnudde V (2017) Rock fabric heterogeneity and its influence on the petrophysical properties of a building limestone: Lede stone (Belgium) as an example. Eng Geol 216. https://doi.org/10.1016/j. enggeo.2016.11.007

Detsch CH (1914) First report to the Beilby Prize Committee of the Institute of Metals, on 'The solidification of metals from the liquid state', 1914, Mar. 18. J. Inst. Metals 11:57-107.

Dewers T. Ortoleva P (1990) Differentiated structures arising from mechanochemical feedback in stressed rocks, Earth-Science Reviews 29:283-298.

Doehne E (1994) In situ dynamics of sodium sulfate hydration and dehydration in stone pores: Observations at high magnification using the environmenta scanning electron microscope. In Conservation of Monuments in the Mediterranean Basin: Stone Monuments, Methodologies for the Analysis of Weathering and Conservation; Proceedings of the 3rd International Symposium, Venice 22-25 June 1994

Doehne E (2002) Salt weathering: a selective review. Geol Soc Lond 205:51-64. https://doi.org/10.1144/gsl.sp.2002.205.01.05

Doehne E, Price CA (2010) Stone conservation: an overview of current research. In: Technical Report, 2nd edn. Getty Conservation Institute, Los Angeles

Doornkamp JC, Brunsden D, Jones DKC (1980) Geology, geomorphology and pedology of Bahrain. Geo Abstracts, Norwich

Doornkamp JC, Ibrahim HAM (1990) Salt weathering. Progress in Physical Geography 14:335-348

Dunn JR, Hudec PP (1966) Water, clay and rock soundness. Ohio J Sci 66:153-168

Duttlinger W, Knöfel D (1993) Salzkristallisation und Salzschadensmechanismen. In Jahresberichte Steinzerfall: Steinkonservierung, Snethlage R. ed. Ernst \& Sohn, Berlin: 197-213.

Espinosa-Marzal RM, Scherer GW (2010) Mechanisms of damage by salt. Geol Soc Lond 331:61-77. https://doi.org/10.1144/sp331.5
Evans IS (1970) Salt crystallization and rock weathering: a review. Rev Géomorphol Dynam 19:153-177

Everett DH (1961) Thermodynamics of frost damage to porous solids. Trans Faraday Soc 57:1541-1551

Farkas O, Siegesmund S, Licha T, Török Á (2018) Geochemical and mineralogical composition of black weathering crusts on limestones from seven different European countries. Environ Earth Sci 77:211. https://doi.org/10.1007/s12665018-7384-8

Fassina V (1994) General criteria for the cleaning of stone: Theoretical aspects and methodology of application. In Stone Material in Monuments: Diagnosis and Conservation; Scuola uniersitaria C.U.M. conservazione dei monumenti, Heraklion Crete, 24-30 May 1993, ed. F. Zezza, 131-138. Bari: Mario Adda Editore

Fitzner B (1988) Porosity properties of naturally or artificially weathered sandstone. In: Ciabach J (ed) International Congress on Deterioration and Conservation of Stone. Torun, Poland, pp 236-245

Fitzner B, Snethlage R (1982) Einfluss der porenradienverteilung auf das verwitterungsverhalten ausgewählter sandsteine. Bautenschutz Bausanierung 5:97-103

Flatt R, Nevin AM, Caruso F, Derluyn H, Desaunaud J, Lubelli B, Espinosa-Marzal RM, Pel L, Rodriguez-Navarro C, Scherer GW (2017) Predicting salt damage in practice: a theoretical insight into laboratory tests. RILEM Technical Letters 2: 108. https://doi.org/10.21809/rilemtechlett.2017.41

Flatt RJ (2002) Salt damage in porous materials: how high supersaturations are generated. J Cryst Growth 242:435-454

Flatt RJ (2003) Salt damage in porous materials: how high supersaturations are generated. J Cryst Growth 242:435-454

Flatt RJ, Scherer GW (2002) Hydration and crystallization pressure of sodium sulfate: a critical review. In: Vandiver PB, Gordway M, Mass JL (eds) Materials Issues in Art and Archeology VI, 712, vol 2011. Cambridge University Press, p II2.2. https://doi.org/10.1557/PROC-712-II2.2

Flatt RJ, Steiger M, Scherer GW (2006) A commented translation of the paper by Correns CW, Steinborn W on crystallization pressure. Environ Geol 52:187-203

Foster WR and Hoover KV (1963) Hexahydrite (MgSO4.6H2O) as an efflorescence of some Ohio dolomites, Ohio J Sci 63:158.

Fusade L, Orr SA, Wood C, O'Dowd M, Viles H (2019) Drying response of limemortar joints in granite masonry after an intense rainfall and after repointing. Herit Sci 7:38. https://doi.org/10.1186/s40494-019-0277-7

Gázquez F, Columbub A, Waele JD, Breitenbach BFM, Huang CR, Shen CC, Lue Y, Calaforra JM, Mleneck-Vautravers M, Hodell DA (2018) Quantification of paleo-aquifer changes using clumped isotopes in subaqueous carbonate speleothems. Chem Geol 493:246-257. https://doi.org/10.1016/j.chemgeo.201 8.05 .046

Genkinger S, Putnis A (2007) Crystallization of sodium sulfate: supersaturation and metastable phases. Environ Geol 52:295-303

Germinario L, Ákos T (2019) Variability of technical properties and durability in volcanic tuffs from the same quarry region - examples from Northern Hungary. Eng Geol 262:105319. https://doi.org/10.1016/j.enggeo.2019.1 05319

Gibeaux S, Vázquez P, De Kock T, Cnudde V, Thomachot-Schneider C (2018) Weathering assessment under $\mathrm{x}$-ray tomography of building stones exposed to acid atmospheres at current pollution rate. Constr Build Mater 168:187198. https://doi.org/10.1016/j.conbuildmat.2018.02.120

Gomez-Heras M, Benavente D, Alvarez de Buergo M, Fort R (2004) Soluble salt minerals from pigeon droppings as potential contribution to the decay of stone based cultural heritage. Eur J Mineral 16:505-509

Gomez-Heras M, Fort R (2007) Patterns of halite ( $\mathrm{NaCl}$ ) crystallization in building stone conditioned by laboratory heating regimes. Environ Geol 52:259-267

Gomez-Heras M, McCabe S (2015) Weathering of stone-built heritage: a lens through which to read the Anthropocene. Anthropocene 11:1-13. https:// doi.org/10.1016/J.ANCENE.2015.12.003

Goudie A, Cooke RU (1984) Salt efflorescences and salt lakes: a distributional analysis. Geoforum 15:563-582

Goudie AS (1974) Further experimental investigation of rock weathering by salt and other mechanical processes. Zeit Geomorph Suppl 21:1-12

Goudie AS (1977) Sodium sulphate weathering and the disintegration of Mohenjo-Daro, Pakistan. Earth Surf Process 2:75-86

Goudie AS (1983) Salt efflorescences and salt weathering in the Hunza Valley, Karakoram Mountains, Pakistan. In: Miller KJ (ed) Proceedings of the International Karakoram Project, vol 2. Cambridge University Press, Cambridge, pp 607-615 
Goudie AS (1985) Salt weathering. Research Paper 33. School of Geography, Oxford: University of Oxford

Goudie AS (1986) Laboratory simulation of "the wick effect" in salt weathering of rock. Earth Surf Process Landf 11:275-285

Goudie AS (1993) Salt weathering simulation using a single-immersion technique. Earth Surf Process Landf 19:369-376

Goudie AS (1999) A comparison of the relative resistance of limestones to frost and salt weathering. Permafr Periglac Process 10:309-316

Goudie AS, Cooke RU, Doornkamp JC (1979) The formation of silt from quartz dune sand by salt weathering processes in deserts. J Arid Environ 2:105-112

Goudie AS, Cooke RU, Evans IS (1970) Experimental investigation of rock weathering by salts. Area 2:42-48

Goudie AS, Day MJ (1980) Disintegration of fan sediments in Death Valley, California, by salt weathering. Phys Geogr 1:126-137

Goudie AS, Jones DKC, Brunsden D (1984) Recent fluctuations in some glaciers of the western Karakoram Mountains, Hunza, Pakistan. In: Miller KJ (ed) Proceedings of the International Karakoram Project, vol 2. Cambridge University Press, Cambridge, pp 411-455

Goudie AS, Viles HA (1995) The nature and pattern of debris liberation by salt weathering: a laboratory study. Earth Surf Process Landf 20:437-449

Goudie AS, Viles HA (1997) Salt weathering hazards. Wiley, Chichester

Goudie AS, Viles HA, Parker AG (1997) Monitoring of rapid salt weathering in the central Namib using limestone blocks. J Arid Environ 37:581-598

Goudie AS, Watson A (1984) Rock block monitoring of rapid salt weathering in southern Tunisia. Earth Surf Process Landf 9:95-98

Grrigs D (1938) The factor of fatigue in rock exfoliation, J Geol 44:781-796

Hamilton A, Hall C (2008) Sodium sulfate heptahydrate: a synchrotron energydispersive diffraction study of an elusive metastable hydrated salt. J Anal At Spectrom 23:840-844. https://doi.org/10.1039/b716734b

Hanus EJ, Louis DK (1968) Thermodynamic effects in the compression of solids, J Pharm Sci 57:677-684.

Honeyborne DB, Harris PB (1958) The structure of porous building stone and its relation to weathering behaviour. Proc. 10th Symp. Colston Res. Soc. 343-359 London: Butterworth Scientific Publications.

Hosono T, Uchida E, Suda C, Ueno A, Nakagawa T (2006) Salt weathering of sandstone at the Angkor monuments, Cambodia: identification of the origins of salts using sulfur and strontium isotopes. J Archaeol Sci 33:11. https://doi. org/10.1016/j.jas.2006.01.018

Ishida T (2001) Acoustic emission monitoring of hydraulic fracturing in laboratory and field. Constr Build Mater 15:283-295

Johannessen CL, Feiereisen JJ Wells AN (1982) Weathering of ocean cliffs by salt expansion in a mid-latitude coastal environment. Shore Beach 50:26-34

Johnstone MA, Sullivan WR, Grant WM (1973) Experimental zinc chloride ocular injury and treatment with disodium edetate, Am J Ophthalmol. 76:137-42.

Kamh GME, Dawood M, El-loly A (2019) Decreasing salt susceptibility index of nummulitic limestone using three resins applied in different ratios and concentrations. Arab J Geosci:12-24. https://doi.org/10.1007/s12517-018-41 61-7 Corpus ID: 133743561

Kirchner G (1996) Cavernou weathering in the Basin and Range area, southwestern USA and Northwestern Mexico. Z Geomorph Suppl. 106:73-97.

Knacke O, Erdberg R (1975) The crystallisation pressure of sodium sulphate decahydrate, A Journal of Deutsche Bunsen-Gesellschaft für Physikalische Chemie 79:645-720

Kozlowski R, Magiera J, Weber J, Haber J (1990) Decay and conservation of Pińczów porous limestone. Part 1. Lithology and weathering. Stud Conserv 35:205-221

Kwaad FJPM (1970) Experiments on the granular disintegration of granite by salt action, vol 16. Amsterdam: University Amsterdam Fysisch Geografischen Bodemkundig Laboratorium Publicatie; pp 67-80

Lager GA, Armbruster T, Rotella FJ, Jorgensen JD, Hinks DG (1984) A crystallographic study of the low-temperature dehydration products of gypsum, CaSO4.2H2O: hemihydrate $\mathrm{CaSO} 4.0 .5 \mathrm{H} 2 \mathrm{O}$, and "-CaSO4. Am Mineral 69:910-918.

La Russa MF, Fermo P, Comite V (2017) The Oceanus statue of the Fontana di Trevi (Rome): The analysis of black crust as a tool to investigate the urban air pollution and its impact on the stone degradation. Sci Total Environ 593594:297-309

Lewin SZ (1982) The mechanism of masonry decay through crystallization. In Conservation of Histric Stone Buildings and Monuments: Report of the Committee on Conservation of Historic Stone Buildings and Monuments, National Materials Advisory Board, Commission on Engineering and
Technical Systems, National Research Council, 120-144. Washington DC: National Academy Press.

Lewis GN and Randall M (1961) Thermodynamics, Rev. by Kenneth SP \& Brewer L, McGraw-Hill, New York, 723p.

Li J, Wang W, Zheng Y (2019) Origin of the Mushroom Stone Forest at the southeastern foot of the Little Sangpu Mountain in eastern Guangdong, China: a palaeo-sea-level indicator or. J Mt Sci 16:487-503. https://doi.org/1 0.1007/s11629-018-5181-1

Linnow K, Zeunert A, Steiger M (2006) Investigation of sodium sulfate phase transitions in a porous material using humidity and temperature controlled $X$-ray diffraction. Anal Chem 78:4683-4689

Lubelli B, Cnudde V, Diaz-Goncalves T, Franzoni E, Hees RPJV, loannou I, Menendez B, Nunes C, Siedel H, Stefanidou M, Verges-Belmin V, Viles H (2018) Towards a more effective and reliable salt crystallization test for porous building materials: state of the art. Mat Structure 51:55. https://doi. org/10.1617/s11527-018-1180-5

Lucas A (1925) Antiques, their restoration and preservation. Arnold E. and Co. London

Luquer LMI (1895) The relative effects of frost and the sulfate of soda efflorescence tests on building stones. Trans Am Soc Civ Eng 33:235-256

Malin MC (1974) Salt weathering on mars. J Geophys Res 79:3889-3894

Maliva RG, Siever R (1988) Diagenetic replacement controlled by force of crystallization. Geology 16:688-691

Mamillian M (1993) Méthodes d'evaluation de l'état d'alterations des pierres desmonuments. In: Thiel MJ (ed) Conservation of Stone and Other Materials, Proceedings of the International RILEM/UNESCO Congress. RILEM Proc, vol 21, pp 775-783

Manohara S, Santhanama M, Chockalingam N (2019) Performance and microstructure of bricks with protective coatings subjected to salt weathering. Const Built Materials 226:94-1065. https://doi.org/10.1016/j. conbuildmat.2019.07.180

Massary G, Massari I (1993) Damp Buildings, Old and New, IICROM, Rome, Italy.

Matsukura Y, Kanai H (1988) Salt fretting in the valley cliff of the Asama volcano region, Japan. Earth Surf Process Landf 13:85-90

Matsukura Y, Matsuoka N (1996) The effect of rock properties on rates of tafoni growth in coastal environments. Zeit Geomorph Suppl Bd 106:57-72

Matsuoka N, Thomachot CE, Oguchi CT, Hatta T, Abe M, Matsuzaki H (2013) Quaternary bedrock erosion and landscape evolution in the Sor Rondane Mountains, East Antarctica: reevaluating rates and processes. Gromorphology 81:408-420. https://doi.org/10.1016/j.geomorph.2006.05.005

McCabe S, Smith BJ, McAlister JJ, Gomez-Heras M, McAllister D, Warke PA, Curran JM, Basheer PAM (2013) Changing climate, changing process: implications for salt transportation and weathering within building sandstones in the UK. Environ Earth Sci 69:1225-1235. https://doi.org/10.1007/S12665-013-2278-2

McIntyre RJ, McTaggart (1979) Comparison of the reactions of atomic and molecular halogens with silver, J Phys Chem 4:866-874.

McGreevy JP (1996) Pore properties of limestones as controls on salt weathering susceptibility: a case study. In: Smith BJ, Warke PA (eds) Processes of urban stone decay. Donhead, London, pp 150-167

McGreevy JP, Smith BJ (1982) Salt weathering in hot deserts: observations on the design of simulation experiments. Geogr Ann 64A:161-170

Menéndez B (2018) Estimators of the impact of climate change in salt weathering of cultural heritage. Geosciences 8:401. https://doi.org/10.3390/ geosciences8110401

Meredith P, Donald AM (1995) Water anomaly in capillary liquid absorption by cement-based materials. J Mat Sci Letter 14:1178-1181

Miller $H$ (1841) The old red sandstone: or new walks in an old field. Edinburgh library.

Mod'd BK, Howarth RJ, Bland CH (1996) Rapid prediction of building research establishment limestone durability class from porosity and saturation. Quart J Eng Geol 29:285-297

Möller D (1990) The Na/CL ratio in rainwater and the seasalt chloride cycle Telllus 42B:254-262

Moore BE (1896) On the Viscosity of Certain Salt Solutions, Phys. Rev. (Series I) 3: 321

Mortensen H (1933) Die "Saltzprengung" und ihreBedeutung für die regional klimatische Gliederung der Wüsten. Petermanns Geogr Mitt 79:130-135

Mosebach R (1951) Neue Ergebnisse zur frage des Wachstums von Kristallen unter einseitigern Druck. Fortschritte de Mineralogie 29 \& 30:25-33.

Mottershead DN 1989, Rates and patterns of bedrock denudation by coastal salt spray weathering: a seven-year record. Earth Surf Process Landf 14:383-398. 
Mustoe GE (1982) Origin of honeycomb weathering. Geol Soc Am Bull 93:108-115 Mustoe GE (1983) Cavernous weathering in the Capital Reef Desert, Utah. Earth Surf Process Landf 8:517-526

Netterberg F, Loudon P (1980) Simulation of salt damage to roads with laboratory model experiments. In: Proceedings of the seventh regional conference for Africa on soil mechanics and foundation engineering, Accra, June 1980, p. 7

Obika B, Freer-Hewish R, Fookes P (1989) Soluble salt damage to thin bituminous road and runway surfaces. Q J Eng GeolHydrogeol 22:59-73.

Oguchi CT (2004) A porosity-related diffusion model of weathering-rind development. Catena 58:65-75. https://doi.org/10.1016/j.catena.2003.12.002

Oguchi CT, Hatta T, Matsukura Y (1999) Weathering rates over 40,000 years based on changes in rock properties of porous rhyolite. Phys Chem Earth A 24:861870 https://www.sciencedirect.com/science/article/pii/S1464189599001283

Ordóñez S, Fort R, García del Cura MA (1997) Pore size distribution and the durability of a porous limestone. Quart J Eng Geol 30:221-230

Owen BB. Brinkly SB (1941) Calculation of the Effect of Pressure upon lonic Equilibria in Pure Water and in Salt Solutions. Chem. Rev. 29:461-474.

Parkus H (1959) Instationaere Waermespannungen, Springer: 168p

Passarge, S (1904) Versuch Einer Physisch-Geographischen Darstellung Der Sandfelder Des S?dafrikanischen Beckens. Dietric Reimer, Berlin. 764p.

Pedro G (1957a) Mécanisme de la désagrégation du granite et de la lave de volvic, sous l'influence des sels de cristallisation. Conptes Rendu Academie des Sciences, Paris 245:333-335

Pedro G (1957b) Nouvelles recherches sur l'influence des sels la désgrégetion des roches. Comptes Rendu Acad Sci 244:2822-2824

Penck A (1891) Geographische Abhandlungen, Volume 5, Nabu Press.

Prebble MM (1967) Cavernous weathering in the Taylor Dry Valley, Victoria Land, Antarctica, Nature 216:1194-1195.

Price CA (1978) The use of sodium sulfate crystallization test for determining the weathering resistance of untreated stone. UNESCO/Rilem International Symposium Determination and Protection of Stone Monuments, Paris

Price CA (1996) Stone conservation: an overview of current research. Research in Conservation. Getty Conservation Institute, Santa Monica http://hdl.handle. net/10020/gci_pub/stone_conservation

Prrikryl R, Přikrylová J, Racek M, Weishauptová A, Kreislová K (2017) Decay mechanism of indoor porous opuka stone: a case study from the main altar located in the St. Vitus Cathedral, Prague (Czech Republic). Environ Earth Sci 76:290. https://doi.org/10.1007/s12665-017-6596-7

Punuru AR, Chowdhury AN, Kulshreshtha NP, Gauri KL (1990) Control of porosity on durability of limestone at the Great Sphinx, Egypt. Environ Geol Water Sci 15:225-232

Pye K, Sperling CHB (1983) Experimental investigation of silt formation by static breakage processes: the effect of temperature, moisture and salt on quartz dune sand and granitic regolith. Sedimentology 30:49-62

Qiang S, Zhang Y (2019) Combined effects of salt, cyclic wetting and drying cycles on the physical and mechanical properties of sandstone. Eng Geol 248:70-79. https://doi.org/10.1016/j.enggeo.2018.11.009

Raneri S, Cnudde V, De Kock T, Derluyn H (2015) X-ray computed microtomography to study the porous structure and degradation processes of a building stone from Sabucina (Sicily). Eur J Mineral 27:279-288. https://doi. org/10.1127/ejm/2015/0027-2433

Richardson BA (1991) The durability of porous stones. Stone Industries 26:22-25

Robinson DA, Williams RBG (1982) Salt weathering of rock specimens of varying shape. Area 14:293-299

Robinson DA, Williams RBG (1996) An analysis of the weathering of Wealden sandstone churches. In: Smith BJ, Warke PA (eds) Processes of urban stone decay. Donhead Publishing, London, pp 133-149

Robinson DA, Williams RBG (2000) Experimental weathering of sandstone by combinations of salts. Earth Surf Process Landf 25:1309-1315

Rodriguez-Navarro C, Doehne E (1999) Salt weathering: influence of evaporation rate, supersaturation and crystallization pattern. Earth Surf Process Landf 24 $191-209$

Rögner K (1986) Temperature measurements of rock surfaces in hot deserts (Negev, Israel). International Geomorphology Part II. Wiley, Chichester, pp $1271-1286$

Rossi-Manaresi R, Tucci A (1991) Pore structure and the disruptive or cementing effect of salt crystallization in various types of stone. Stud Conserv 36:53-58

Ruiz-Agudo E, Putnis CV, Pel L, Rodriguez-Navarro C (2012) Template-assisted crystallization of sulfates onto calcite: implications for the prevention of salt damage. Crystal Growth Design 13:40-51
Sayward JM (1984) Salt action on concrete. U.S. army cold regions research and engineering laboratory, Special Rpt. 84-25, p. 76.

Schaffer RJ (1932) The weathering of natural building stones. Department of Scientific and Industrial Research. Building Research. Special Report 18, HM Stationary Office, London. J Soc Chem Industry 51:1068-1069. https://doi. org/10.1002/jctb.5000515211 Accessed by Wiley Online Library

Schbnikov AV (1935) Trudy Lomonosov Inst. Akad. Naul SSSR 17-21

Scherer GW (1995) Fundamentals of drying and shrinkage. Proceedings of the Science of whitewares conference. Amer Ceramic Soc

Scherer GW (1999) Crystallization in pores. Cem Concr Res 29:1347-1358

Scherer GW (2004) Stress from crystallization of salt. Cem Concr Res 34:1613-1624

Scherer GW (2006) Internal stress and cracking in stone and masonry. Springer: In: KonstaGdoutos MS (ed) Measuring, monitoring and modeling concrete properties, Proc 16th European Conference of Fracture, Alexandropoulis; pp 669-673

Schiro M, Ruiz-Agudo E, Rodriguez-Navarro C (2012) Damage mechanisms of porous materials due to inpore salt crystallization. Phys Rev Lett 109:26503. https://doi.org/10.1103/PhysRevLett.109.265503

Shahidzadeh-Bonn N, Desarnaud J, Bertrand F, Chateau X, Bonn D (2010) Damage in porous media due to salt crystallization. Phys Rev E 81:066110. https://doi.org/10.1103/PhysRevE.81.066110

Siegesmund S, Snethlage R (2014) Stone in architecture: properties, durability. Springer-Verlag, Berlin Heidelberg

Smith BJ, McGreevy JP (1988) Contour scaling of a sandstone by salt weathering under simulated hot desert conditions. Earth Surf Process Landf 13:697-705

Snethlage R, Wendler E (1997) Moisture cycles and sandstone degradation. In: Baer NS, Snethlage R (eds) Saving our architectural heritage - the conservation of historic stone structures. Elsevier, Chichester, pp 7-24

Sperling CHB, Cooke RU (1980a) Salt weathering in arid environments I: theoretical considerations. Bedford College, University of London, Papers in Geography 8.

Sperling CHB, Cooke RU (1980b) Salt weathering in and environments: experimental investigations of the relative importance of hydration and crystallization processes. I Theoretical considerations. Bedford College London, Papers in Geography 8: 53p

Sperling CHB, Cooke RU (1985) Laboratory simulation of rock weathering by salt crystallization and hydration processes in hot, arid environments. Earth Surf Process Landf 10:541-555

Steiger M (2005a) Crystal growth in porous materials - I: the crystallization pressure of large crystals. J Cryst Growth 282:455-469

Steiger M (2005b) Crystal growth in porous materials - II: influence of crystal size on the crystallization pressure. J Cryst Growth 282:470-481

Steiger M, Asmussen S (2008) Crystallization of sodium sulfate phases in porous materials: the phase diagram $\mathrm{Na} 2 \mathrm{SO} 4-\mathrm{H} 2 \mathrm{O}$ and the generation of stress. Geochim Cosmochim Acta 72:4291-4306

Steiger M, Charola AE, Sterflinger K (2014) Weathering and deterioration. In: Siegesmund S, Snethlage R (eds) Stone in architecture - properties, durability, 5th edn. Springer, Berlin, pp 225-316

Steiger M, Linnow K, Juling H, Gülker G, El Jarad A, Brüggerhoff S, Kirchner D (2008) Hydration of $\mathrm{MgSO}_{4} \mathrm{H}_{2} \mathrm{O}$ and generation of stress in porous materials. Crystal Growth Design 8:336-343

Suzuki T (2002) Rock control in geomorphological processes: research history in Japan and perspective. Trans Japan Geomorph Union 23:161-199

Taber S (1916) The growth of crystals under external pressure. Am J Sci 41A:532-557

Tada R, Maliva R, Siever R (1987) A new mechanism, for pressure solution in porous quartzose sandstone. Geochim Cosmochim Acta 51:2295-2301

Thaulow N, Sahu S (2004) Mechanism of concrete deterioration due to salt crystallization. In: Broekmans MATM (ed) Proc 9th Euroseminar on Microscopy Applied to Building Materials, Special Issue of Materials Characterization 53. Elsevier, Trondheim, pp 123-127

Theoulakis P, Moropoulou A (1997) Microstructural and mechanical parameters determining the susceptibility of porous building stones to salt decay. Const Build Materials 11:65-71

Thomachot-Schneider C, Huby E, Chalons K, Drothière X, Vazquez P (2018) Role of the capillary fringe on the dilatation of a low porosity limestone submitted to unidirectional freezing. Prog Earth Planet Sci 5:1-10. https://doi. org/10.1186/s40645-018-0213-6

Thompson J (1862) The disintegration of stones exposed in buildings and otherwise to atmospheric influence, Report of the Annual Meeting. British Association for the Advancement of Science, London

Thury H (1828) Sur le procédé propose par M. Brard pour reconnaître, immédiatement, les pierres qui ne peuvent pas resister à la gelée. Ann Chim Phys 38:160-192 
Tillar FM (1991) Mechanisms of flow through compressible porous beds in sedimentation, filtration, centrifugation, deliquoring, and ceramic processing. Report of office of basic Energy, Dept. Energy, 21p.

Török A, Licha T, Simon K, Siegesmund S (2011) Urban and rural limestone weathering; the contribution of dust to black crust formation. Environ Earth Sci 63:675-693. https://doi.org/10.1007/s12665-010-0737-6

Török A, Szemerey-Kiss B (2019) Freeze-thaw durability of repair mortars and porous limestone: compatibility issues. Prog Earth Planet Sci 6:1-12. https:// doi.org/10.1186/s40645-019-0282-1

Trenhaile AS (1987) The geomorphology of rocky coasts. Clarendon Press, Oxford

Tricart J (1960) Expériences de désagégation de roches granitiques par la cristallisation du sel marin. Zeit Geomorph Suppl Bd 1:239-240

Tsui N, Flatt RJ, Scherer GW (2003) Crystallization damage by sodium sulfate. J Cult Herit 4:109-115

Van Grieken R (2003) Patterns of damage in igneous and sedimentary rocks under conditions simulating sea-salt weathering. Earth Surf Process Landf 28:1-14

Vos BH (1976) Water absorption and drying of materials. In: Rossi-Manaresi R (ed) The Conservation of Stone I. Centro per la Conservazione delle Sculture All'Apperto, Bologna, pp 679-694

Weast RC (1967) CRC Handbook of Chemistry and Physics 48th Edition.

Weber H (1984) Mauerfeuchtigkeit. Expert Verlag, Sindelfingen, pp 15-37

Wellman HW, Wilson AT (1965) Salt weathering, a neglected geological erosive agent in coastal and arid environments. Nature 205:1097-1098

Weyl PK (1959) Pressure solution and the force of crystallization - a phenomenological theory. J Geophys Res 64:2001-2005.

Wilhelmy H (1958) Klimamorphologie der Massengesteine. G. Westermann Verlag. Braunschweig.

Williams RBG, Robinson DA (1981) Weathering of sandstone by the combined action of frost and salt. Earth Surf Process Landf 6:1-9

Williams RBG, Robinson DA (1998) Weathering of sandstone by alunogen and alum salts. Quart J Eng Geology 31:369-373

Williams RBG, Robinson DA (2001) Experimental frost weathering of sandstone by various combinations of salts. Earth Surf Process Landf 26:811-818

Winkler EM (1994) Stone in architecture. Springer-Verlag, Berlin

Winkler EM (1973) Stone: Properties, Durability in Man's Environment. SpringerVerlag, 230p

Winkler EM (1975) Stone: Properties, Durability in Man's Environment. 2nd rev. ed. Applied Mineralogy 4. New York: Springer-Verlag

Winkler EM, Singer PC (1972) Crystallization pressure of salts of stone and concrete. Geol. Soc. Amer. Bull, v. 83, no. 11, p. 3509-3514

Winkler EM, Wilhelm EJ (1970) Salt burst by hydration pressure in architectural stone in urban atmosphere, Geol. Soc. Amer. Bull. 81:567-572

Yatsu E (1988) The nature of weathering: an introduction. Sozosha, Tokyo Yokoyama T, Kimura J, Mitsuguchi T, Danhara T, Hirata T, Sakata S, Iwano H, Maruyama S, Chang Q, Miyazaki T, Murakami H, Kokubu Y (2018) U-Pb dating of calcite using LA-ICP-MS; Instrumental setup for non-matrix-matched age dating and determination of analytical areas using elemental imaging. Geochem J 55:531-540. https://doi.org/10.2343/geochemj.2.0541

Yu S, Oguchi CT (2010a) Role of pore size distribution in salt uptake, damage, and predicting salt susceptibility of eight types of Japanese building stones. Eng Geol 115:226-236

Yu S, Oguchi CT (2010b) Is sodium sulphate invariably effective in destroying any type of rock? Geol Soc London Special Publ 333:43-58

Yu S, Oguchi CT (2013) Is sheer thenardite attack impotent compared with cyclic conversion of thenardite-mirabilite mechanism in laboratory simulation tests? Eng Geol 152:148-154

Zehnder K, Arnold A (1989) Crystal growth in salt efflorescence. J Cryst Growth 97:513-521

Zehnder K (1996) Gypsum efflorescence in the zone of rising damp. Monitoring of slow decay processes caused by crystallizing salts on wall paintings. In: 8th International Congress on deterioration and conservation of stone, Berlin, 1996. pp 1669-1678

Zehnder K (1993) New aspects of decay caused by crystallization of gypsum, Conservation of Stone and Other materials, Edit. RILEM, vol. 1, Causes of Disorders and Diagnosis, Paris, pp 107-114

\section{Publisher's Note}

Springer Nature remains neutral with regard to jurisdictional claims in published maps and institutional affiliations.

\section{Submit your manuscript to a SpringerOpen ${ }^{\circ}$ journal and benefit from:}

- Convenient online submission

- Rigorous peer review

- Open access: articles freely available online

- High visibility within the field

- Retaining the copyright to your article

Submit your next manuscript at $\boldsymbol{\nabla}$ springeropen.com 